\title{
Marine cyanolichens from different littoral zones are associated with distinct bacterial communities
}

Nyree J West ${ }^{\text {Corresp., }}{ }^{1}$, Delphine Parrot ${ }^{2}$, Claire Fayet ${ }^{1}$, Martin Grube ${ }^{3}$, Sophie Tomasi ${ }^{2}$, Marcelino T Suzuki

${ }^{1}$ Observatoire Océanologique de Banyuls sur mer, Sorbonne Université, CNRS, Banyuls sur mer, France

2 Institut des Sciences Chimiques de Rennes, Université Rennes I, Rennes, France

3 Institute of Plant Sciences, University of Graz, Graz, Austria

${ }^{4}$ Laboratoire de Biodiversité et Biotechnologies Microbiennes (LBBM), Sorbonne Université, CNRS, Banyuls sur mer, France

Corresponding Author: Nyree J West

Email address: nyree.west@obs-banyuls.fr

The microbial diversity and function of terrestrial lichens has been well studied, but knowledge about the non-photosynthetic bacteria associated with marine lichens is still scarce. 16S rRNA gene Illumina sequencing was used to assess the culture-independent bacterial diversity in the strictly marine cyanolichen species Lichina pygmaea and Lichina confinis, and the maritime chlorolichen species Xanthoria aureola which occupy different areas on the littoral zone. Inland terrestrial cyanolichens from Austria were also analysed as for the marine lichens to examine further the impact of habitat/lichen species on the associated bacterial communities. The $L$. confinis and $L$. pygmaea communities were significantly different from those of the maritime Xanthoria aureola lichen found higher up on the littoral zone and these latter communities were more similar to those of the inland terrestrial lichens. The strictly marine lichens were dominated by the Bacteroidetes phylum accounting for $50 \%$ of the sequences, whereas Alphaproteobacteria, notably Sphingomonas, dominated the maritime and the inland terrestrial lichens. Bacterial communities associated with the two Lichina species were significantly different sharing only 33 core OTUs, half of which were affiliated to the Bacteroidetes genera Rubricoccus, Tunicatimonas and Lewinella, suggesting an important role of these species in the marine Lichina lichen symbiosis. Marine cyanolichens showed a higher abundance of OTUs likely affiliated to moderately thermophilic and/or radiation resistant bacteria belonging to the Phyla Chloroflexi, Thermi, and the families Rhodothermaceae and Rubrobacteraceae when compared to those of inland terrestrial lichens. This most likely reflects the exposed and highly variable conditions to which they are subjected daily. 


\section{Marine cyanolichens from different littoral zones 2 are associated with distinct bacterial 3 communities}

4 Nyree J. West ${ }^{\star 1}$, Delphine Parrot ${ }^{2 \dagger}$, Claire Fayet ${ }^{1}$, Martin Grube ${ }^{3}$, Sophie Tomasi ${ }^{2}$ and 5 Marcelino T. Suzuki ${ }^{4}$

$6{ }^{1}$ Sorbonne Universités, UPMC Univ Paris 06, CNRS, Observatoire Océanologique de Banyuls (OOB), F7 66650, Banyuls sur mer, France

82 UMR CNRS 6226, Institut des Sciences chimiques de Rennes, Equipe CORINT «Chimie Organique et 9 Interfaces », UFR Sciences Pharmaceutiques et Biologiques, Univ. Rennes 1, Université Bretagne Loire, 10 F-35043, Rennes, France

$11{ }^{3}$ Institute of Plant Sciences, University of Graz, A-8010 Graz, Austria

$12{ }^{4}$ Sorbonne Universités, UPMC Univ. Paris 06, CNRS, Laboratoire de Biodiversité et Biotechnologies 13 Microbiennes (LBBM), Observatoire Océanologique, F-66650, Banyuls sur mer, France

14 tCurrent address: GEOMAR Helmholtz Centre for Ocean Research Kiel, Research Unit Marine Natural 15 Products Chemistry, GEOMAR Centre for Marine Biotechnology, 24106 Kiel, Germany

$16{ }^{*}$ Corresponding author:

17 Observatoire Océanologique de Banyuls sur mer, F-66650 Banyuls sur mer, France

18 Tel: +33 (0)4 301924 29, Fax: +33 (0)4 68887398

19 Email: nyree.west@obs-banyuls.fr 


\section{Abstract}

22 The microbial diversity and function of terrestrial lichens has been well studied, but 23 knowledge about the non-photosynthetic bacteria associated with marine lichens is still 24 scarce. 16S rRNA gene Illumina sequencing was used to assess the culture-independent 25 26 bacterial diversity in the strictly marine cyanolichen species Lichina pygmaea and Lichina confinis, and the maritime chlorolichen species Xanthoria aureola which occupy different areas on the littoral zone. Inland terrestrial cyanolichens from Austria were also analysed as for the marine lichens to examine further the impact of habitat/lichen species on the associated bacterial communities. The $L$. confinis and L. pygmaea communities were significantly different from those of the maritime Xanthoria aureola lichen found higher up on the littoral zone and these latter communities were more similar to those of the inland terrestrial lichens. The strictly marine lichens were dominated by the Bacteroidetes phylum accounting for $50 \%$ of the sequences, whereas Alphaproteobacteria, notably Sphingomonas, dominated the maritime and the inland terrestrial lichens. Bacterial communities associated with the two Lichina species were significantly different sharing only 33 core OTUs, half of which were affiliated to the Bacteroidetes genera Rubricoccus, Tunicatimonas and Lewinella, suggesting an important role of these species in the marine Lichina lichen symbiosis. Marine cyanolichens showed a higher abundance of OTUs likely affiliated to moderately thermophilic and/or radiation resistant bacteria belonging to the Phyla Chloroflexi, Thermi, and the families Rhodothermaceae and Rubrobacteraceae when compared to those of inland terrestrial lichens. This most likely reflects the exposed and highly variable conditions to which they are subjected daily. 


\section{Introduction}

44

The lichen symbiosis, commonly recognised as a partnership of a fungus (mycobiont), and a photosynthetic partner (photobiont) arose with the conquest of land in the lower Devonian, according to the first clear fossil evidence (Honegger, Edwards \& Axe, 2013). The enclosure of the photobiont partner by protective layers of the fungal partner gave rise to a new morphological structure. This symbiotic structure is called the lichen thallus, which apparently mediates a high degree of tolerance to desiccation (Kranner et al., 2008), and allows many lichens to thrive as poikilohydric organisms in environments characterised by periodic changes in environmental conditions. Therefore, lichens are typically found in habitats where other organisms struggle to persist such as the intertidal belt of coastal rocks, where lichens develop characteristically coloured belts.

Bacteria were already found in the oldest microfossils that can be reliably assigned to lichen thalli (Honegger, Edwards \& Axe, 2013), an observation that fits well with the observations of bacterial colonisation of extant lichens (Cardinale et al., 2008). Recent works suggest that the ubiquitous presence of bacteria in lichen thalli contributes to a more complex functional network beyond the interaction of fungi and algae (Aschenbrenner et al., 2016). Bacteria were first cultured from lichens many years ago and were originally supposed to be involved in nitrogen-fixation (Henkel \& Yuzhakova, 1936). However, due to the low culturability of bacteria from many environments (Ferguson, Buckley \& Palumbo, 1984) and the tendency of culture methods to select for opportunistic species which rarely dominate in the natural environment (Eilers, Pernthaler \& Amann, 2000), their diversity was only recently fully recognised.

Culture-independent molecular studies of lichen microbial diversity as well as microscopic observations revealed that bacteria belonging to the Alphaproteobacteria were the dominant microbial group associated with the lichens (Cardinale, Puglia \& Grube, 2006; Liba et al., 2006; Grube et al., 2009; Bjelland et al., 2011; Hodkinson et al., 2012; Cardinale et al., 2012a). In these studies, high abundances of Alphaproteobacteria were generally observed on the surface structures of the lichen thalli although some were observed in the fungal hyphae. More recently, the application of high-throughput sequencing techniques to lichen bacterial community analysis confirmed that the composition of the lichen bacterial communities could be more influenced by the 
74 mycobiont species than by their sample site (Bates et al., 2011), by the photobiont 75 (Hodkinson et al., 2012), and also by the position in the lichen thallus (Mushegian et al., 76 2011).

77 Lichens exhibit clear specificity for substrate and microhabitat conditions, and a clear 78 example of habitat specialisation can be observed for marine lichens, which show vertical 79 zonation in four characteristic belts along rocky coastlines (also known as sublittoral, 80 littoral, supra-littoral and terrestrial zones (Fletcher, 1973a,b). The common littoral lichen Lichina pygmaea is immersed for several hours each day whereas Lichina confinis occurs higher up in the littoral zone, where it is perpetually subjected to splashing and sea-spray and submerged only during short periods of high tides. Xanthoria spp. can also occur in this zone and in the xeric supralittoral zone, which is exposed to sea-spray during storms 85 but not submerged in seawater. Therefore, marine lichen species certainly experience 86 different levels of stress, ranging from direct sunlight exposure, temperature, salinity and wind variation according to their position in the littoral zone (Delmail et al., 2013).

The genus Lichina belongs to the class Lichinomycetes and is composed of both 89 strictly marine and non-marine species (Schultz, 2017). The marine species L. confinis and L. pygmaea harbour cyanobacterial photobionts closely related to strains of the genus Rivularia (Ortiz-Álvarez et al., 2015). Even though the two lichen species above show a similar distribution range, their cyanobionts belong to separate groups that do not overlap at the OTU or even at the haplotype level (Ortiz-Álvarez et al., 2015). Apart from the cyanobacterial photobiont, the composition of the bacteria associated with marine lichens is poorly studied when compared to those of inland lichens. So far, only Hydropunctaria maura, which forms the black belt on littoral zones, was included in a culture-independent study (Bjelland et al., 2011). Bacterial communities of this lichen were different from inland terrestrial lichens, with higher relative abundances of Actinobacteria, Bacteroidetes, Deinococcus, and Chloroflexi. A recent study of Icelandic marine lichens focused on culturable bacteria, but also revealed by fingerprinting (DGGE) analysis of 16S rRNA genes that the bacterial communities were different among different marine lichen species (Sigurbjornsdottir et al., 2014).

Such differences could be of interest for bioprospecting approaches since lichens are 104 known to be a rich source of natural products (Boustie \& Grube, 2005; Parrot et al., 2016). 
105 However, lichen-associated bacteria have only recently been discovered as an additional 106 contributor to the lichen chemical diversity, and even though only few lichen-associated 107 bacteria have been studied carefully in this respect, many of them produce secondary 108 metabolites. Some of their compounds have pronounced bioactive properties [see 109 (Suzuki et al., 2016)) for a review]. Nevertheless, the role of these compounds in the 110 symbiosis is not well understood at this stage. So far, bioprospecting of the marine lichens

111 L. pygmaea and L. confinis (and Roccella fuciformis) was carried out by a cultivation112 based approach targeting Actinobacteria that led to the isolation of 247 bacterial species 113 including 51 different Actinobacteria (Parrot et al., 2015).

114 To address the paucity of knowledge on the total diversity and variation of bacteria 115 associated with marine lichens and to provide a base for future bioprospecting efforts, the uncultured microbial communities of the cyanolichen species $L$. confinis and L. pygmaea

117 and the chlorolichen species $X$. aureola and $X$. parietina were characterised by Illumina 118 sequencing of $16 S$ rRNA gene fragments. In addition, other inland terrestrial cyanolichen species were characterised in parallel to allow us to address the following questions: i) 120 what are the major bacterial groups associated with the marine and maritime lichens 121 occupying different heights on the littoral zone; ii) how does the culturable fraction of 122 bacteria from Lichina spp. and L. auriforme compare to the total bacterial community 123 associated with these species; and iii) do inland terrestrial cyanolichens share a 124 significant proportion of their symbionts with marine cyanolichens? 


\section{Materials \& Methods}

126 Sampling design and sample collection

127 The marine cyanolichens Lichina pygmaea and Lichina confinis were collected on 16 128 October 2013 from the Houssaye Point, Erquy on the coast of Brittany, France (Table 1, 129 Fig. 1). Lichens were sampled in triplicate in a $3 \mathrm{~m}$ radius zone that we defined as a 130 sample cluster. Two other sample clusters of triplicates were sampled further along the 131 littoral zone. For $L$. confinis, sample clusters 1 and 2 were $22 \mathrm{~m}$ apart and clusters 2 and 1323 were $14.4 \mathrm{~m}$ apart. For L. pygmaea, clusters 1 and 2 , and 2 and 3 , were both separated 133 by $6 \mathrm{~m}$. Duplicate seawater samples were also taken using sterile $50 \mathrm{ml}$ centrifuge tubes.

134 Similarly, one cluster of three Xanthoria aureola samples were also taken from Houssaye 135 Point and another cluster of Xanthoria parietina was sampled from the rocky coastline of 136 Banyuls-sur-mer on the Mediterranean Sea (Table 1, Table S1). The inland terrestrial 137 cyanolichens were sampled at Kesselfalklamm, Austria. Lathagrium auriforme and 138 Scytinium lichenoides were sampled in the shaded humid zone near to a river whereas

139 Lathagrium cristatum and Lathagrium fuscovirens were collected from rocks in an 140 exposed dry zone (Table1, Table S1, Fig. 1). Lichens were sampled using a sterile 141 scalpel and gloves, placed in sterile bags and stored at $-80^{\circ} \mathrm{C}$.

142 The morphological identification of the lichens was verified by sequencing the marker 143 genes ITS-5.8S rRNA (White et al., 1990) for the marine and maritime lichens and the 144 genes beta-tubulin (Myllys, Lohtander \& Tehler, 2001) and nuclear LSU rRNA (Vilgalys \& 145 Hester, 1990; Otálora et al., 2010) for the inland terrestrial lichens (Supplementary 146 Information, Table S2).

147 DNA extraction

148 Genomic DNA was extracted using the DNeasy PowerPlant Pro DNA Isolation Kit 149 (Qiagen S.A.S., Courtaboeuf, France). Lysis was achieved by first grinding the lichens 150 (several pieces selected randomly from each thallus amounting to approximately $0.1 \mathrm{~g}$ of 151 material) to a powder with liquid nitrogen using a sterile pestle and mortar. The powder 152 was added to the lysis tubes of the kit following the protocol according to the 153 manufacturer's instructions, including a heating step of $65^{\circ} \mathrm{C}$ for $10 \mathrm{~min}$ before the 154 addition of the RNase A solution. Homogenisation was achieved using a standard vortex 155 equipped with a flat-bed vortex pad. DNA quality was verified by agarose gel 
156 electrophoresis and DNA was quantified using the Quant-iT ${ }^{\mathrm{TM}}$ PicoGreen ${ }^{\circledR}$ dsDNA Assay 157 Kit (Invitrogen, Thermo-Fisher Scientific Inc., Courtaboeuf, France) according to 158 manufacturer's instructions.

159 PCR amplification of $16 S$ rRNA genes and illumina sequencing

160 Bacterial 16S rRNA gene fragments were amplified using the primer pair 341F 161 (CCTACGGGNGGCWGCAG) and 805R (GACTACHVGGGTATCTAATCC) which show 162 the best combination of domain and phylum coverage (Klindworth et al., 2012). The 341F 163 primers were tagged at the 5 ' end with different $7 \mathrm{bp}$ tags for each sample (Table S3), 164 and that were chosen from a set of tags designed to be robust to substitution, deletion 165 and insertion errors incurred in massively parallel sequencing (Faircloth \& Glenn, 2012). We also included in parallel a control consisting of DNA from a synthetic mock community 168 (Mock) of 20 bacterial species containing equimolar (even) rRNA operon counts (HM782D; Genomic DNA from Microbial Mock Community B, Even, Low Concentration, BEI Resources, Manassas, VA. This standard is now obtainable from LGC Standards S.a.r.I., Molsheim, France; reference ATCC $®$ MSA-1002 ${ }^{\mathrm{TM}}$ ). Between 1-10 ng of each DNA sample (or $1 \mu$ of Mock DNA) were amplified in duplicate $10 \mu$ reactions containing $1 \mathrm{X}$ KAPA 2G Fast Ready Mix (Merck, Darmstadt, Germany) and $0.5 \mu \mathrm{M}$ of each primer. The PCR cycling conditions were $95^{\circ} \mathrm{C}$ for 3 min followed by 25 cycles of $95^{\circ} \mathrm{C}$ for $15 \mathrm{~s}, 55^{\circ} \mathrm{C}$ for $15 \mathrm{~s}$ and $72{ }^{\circ} \mathrm{C}$ for $2 \mathrm{~s}$, and a final extension of $72{ }^{\circ} \mathrm{C}$ for $30 \mathrm{~s}$. Duplicate reactions were pooled, and PCR amplification verified by gel electrophoresis. To normalise the samples before pooling and sequencing, the Sequalprep Normalization Plate (96) kit (Invitrogen) was used according to manufacturer's instructions. After binding, washing and elution, the 37 environmental samples and the mock DNA sample were pooled into one tube. The clean-up of the PCR amplicon pool was achieved with the Wizard SV Gel and PCR CleanUp System (Promega, Charbonnières-les-Bains, France) according to manufacturer's instructions with elution in $30 \mu \mathrm{l}$ of molecular biology grade water (Merck). DNA was quantified with the Quant-iT PicoGreen dsDNA Assay kit (Invitrogen) according to manufacturer's instructions. Approximately $350 \mathrm{ng}$ DNA was pooled with $700 \mathrm{ng}$ of barcoded PCR products from a different project (sequencing the 16S rRNA genes of marine bacterioplankton) and sent out to the sequencing company Fasteris (Geneva, Switzerland) for library preparation and sequencing. Library preparation involved ligation 
187 on PCR using the TruSeq DNA Sample Preparation Kit (Illumina, San Diego, CA) 188 according to manufacturer's instructions except that 5 PCR cycles were used instead of 18910 cycles. The library was sequenced on one Illumina MiSeq run using the $2 \times 300 \mathrm{bp}$ 190 protocol with MiSeq version 3.0 chemistry and the basecalling pipeline MiSeq Control 191 Software 2.4.1.3, RTA 1.18.54.0 and CASAVA-1.8.2. The error rate was measured by 192 spiking the library with about $0.5 \%$ of a PhiX library and mapping the reads onto the PhiX 193 reference genome.

194 Sequence pre-processing

195 Paired-end Illumina sequence data was processed with a custom pipeline 196 (Supplementary Information) using mainly the USEARCH-64 version 8 package (Drive5; 197 Tiburon, CA) with some commands from QIIME version 1.9.1 (Caporaso et al., 2010) and 198 mothur version 1.33.3 (Schloss et al., 2009). Analysis of the Mock data set first allowed 199 us to calibrate the different steps of the sequence processing pipeline ensuring that the 200 assigned OTUs reflected as closely as possible the defined composition of the sample 201 and allowed us to reveal potential sequencing artifacts (errors, contamination). To 202 minimise errors and reduce over-inflation of diversity, the following criteria were chosen 203 in the pre-processing steps; a) zero mismatches allowed in the overlapping region when 204 merging the paired end reads, b) quality filtering was carried out after merging using a 205 stringent expected error of 1.0 (Edgar \& Flyvbjerg, 2015), c) zero mismatches allowed in 206 the barcode when demultiplexing, d) exact matches to both primers required, e) removal of singleton sequences that are expected to have errors and that increase the number of 208 spurious OTUs (Edgar, 2013). Sequence data was submitted to the European Nucleotide 209 Archive under the study number: PRJEB23513.

210 Sequence data analysis

211 OTUs were defined with the UPARSE algorithm, part of the USEARCH-64 package, 212 which clusters sequences with $>97 \%$ identity to OTU centroid sequences (representative 213 sequences that were selected based on their rank of read abundance after dereplication) 214 and that simultaneously removes chimeras (Edgar, 2013). Subsequent analysis steps were performed in QIIME or MACQIIME version 1.9.1. OTU taxonomy was assigned with 216 the RDP classifier using the GreenGenes OTU database (gg_13_8_otus) defined at 97\% 217 identity. For the lichen dataset, the OTU table was filtered to remove eukaryotic, archaeal 
218 and organelle sequences (chloroplast, mitochondria). Due to the presence of the lichen 219 photobiont, a large number of cyanobacterial sequences were recovered. The OTU table 220 was filtered to separate non-cyanobacteria sequences from the cyanobacteria 221 sequences. The representative sequences were aligned using the PYNAST aligner in 222 QIIME and the 13_8 GreenGenes alignment (Supplementary Information), and the OTU 223 table was further pruned by removing non-aligning OTUs. Data exploration and analysis 224 was carried out with QIIME (see Supplementary Information) and with the packages 225 Phyloseq (McMurdie \& Holmes, 2013) and vegan (Oksanen et al., 2013) in R (R. Core 226 Team, 2015). One-way ANOSIM tests were performed using the vegan package in $R$ to 227 determine significant differences between groups. To examine the patterns of 228 phylogenetic relatedness of the lichen-associated bacterial communities, the mean 229 pairwise distance (MPD) and the mean nearest taxon distance (MNTD) were calculated 230 using the Picante package in R (Kembel et al., 2010). Whereas MPD calculates the mean 231 pairwise distance between all OTUs in each community, MNTD calculates the mean 232 distance between each OTU in the community and its closest relative. To test the 233 significance of the phylogenetic community structure observed, the standardised effect 234 size (SES) was then calculated for the MPD and MNTD to compare the observed pattern 235 to that of a null model of phylogeny. We used the null model of randomly shuffling the tip 236 labels. SES $S_{(M P D)}$ and $\operatorname{SES}_{(\mathrm{MNT})}$ are equivalent to -1 times the Net Relatedness Index 237 (NRI) and the Nearest Taxon Index (NTI) respectively, reported previously (Webb, 238 Ackerly \& Kembel, 2008).

239 Since analysis of the Mock data revealed the presence of contaminant and/or sequences 240 from a library from another project, potentially due to cross-talk during the Illumina 241 sequencing, OTUs exhibiting a low uniform abundance amongst all the samples were 242 filtered out by calculating between-sample variance on a relative abundance OTU table 243 and removing those OTUs with a variance of $<1 \times 10^{-6}$.

244 Comparison of sequences with cultured species, and the $\mathrm{NBCl}$ database

245 The 16S rRNA gene sequences of 247 bacterial strains previously isolated from the 246 lichens L. pygmaea, L. confinis, and L. auriforme (Parrot et al., 2015) were compared to 247 the sequences from this study by blastn (Altschul et al., 1997) queries against a database 248 of the representative OTU sequences in the current study using the standalone version 
249 of NCBI blast. The bacterial strains were isolated from the lichens in France and Austria 25018 months and 12 months respectively before those sampled in this study, but they were 251 sampled at exactly the same sites. Note that in the previous study (Parrot et al., 2015), 252 the lichen L. auriforme was cited with its previous name; C. auriforme (Collema 253 auriforme).

254

255 In addition, the sequences of the top 30 OTUS from the strict marine or maritime-inland 256 terrestrial lichens were subjected to blastn queries against the NCBI Genbank $\underline{n t}$ 257 database.

258

259 
260 Results

\section{Control of sequence quality and data treatment}

262 The mock community sequences were parsed out and analysed separately from the 263 other sequences obtained from the lichen and seawater samples. Analysis of the 20-

264 species mock community allowed us to check for potential contamination and also to 265 refine our bioinformatic analysis pipeline to obtain the expected number and identity of OTUs. Using the criteria described in the methods and the algorithm UPARSE of the USEARCH package for clustering OTUs at $97 \%$ identity, we obtained 19 OTUs (identical

268

269

270

271

272

273

274

275

276

277

278

279

280

281

282

283

284

285

286

287

288

289

to the reference sequence (Edgar, 2013)) which perfectly corresponded to the mock community (the two Staphylococcus sp. strains cluster together) plus 17 other OTUs. The 19 mock OTUs accounted for $99.5 \%$ of the sequences. Of the remaining 17 OTUs, 4 were affiliated to the Cyanobacteria class and 3 to chloroplasts that were the dominant OTUs found respectively in the lichen samples (this study) and in samples from the offshore bacterioplankton study loaded in the same MiSeq run. This is evidence of the sequencing artifact termed "cross-talk" which can be due to index misassignment where reads from one sample are wrongly assigned the indexes from a different sample. The remaining 10 mock OTUs accounted for $0.24 \%$ of the reads.

After the different sequence processing steps on the lichen and seawater samples, a total of 509656 good quality sequences obtained were clustered into 93 cyanobacterial OTUs and 2519 bacterial OTUs. Examination of the OTU tables of the study samples also revealed cross-talk OTUs as observed in the mock sample that were mainly attributed to chloroplasts and cyanobacteria. This problem was partly resolved by removal of these lineages for subsequent analysis of the heterotrophic bacterial diversity but there were nevertheless some bacterioplankton OTUs present at consistently low abundances in all the lichen samples, which are dominant in the samples from different study (e.g., Pelagibacteraceae). Therefore, for certain analyses, the OTU table was filtered for low variance OTUs which allowed the removal of spurious OTUs. This data treatment would also have removed non-spurious low abundance OTUs but as our analysis was focused on the dominant (most abundant) OTUs and not the rare OTUs, this would not affect our major findings. 
As expected for cyanolichens, a high proportion of the sequences were affiliated to 291 the Cyanobacteria lineage (including chloroplasts) and ranged from 30-60\% for the 292 marine lichens and from $40-85 \%$ for the inland terrestrial lichens (Fig. S1). The 293 cyanobacterial sequences were then removed for further analyses. The number of non294 cyanobacteria bacterial sequences per sample ranged from 2759 for $L$. auriforme to $295>14000$ sequences for $X$. aureola.

296

\section{Bacterial communities associated with lichens in different areas of the littoral zone}

For clarity, we use the term "marine lichens" to refer to the two Lichina species that are strictly marine, "maritime lichens" to refer to the two Xanthoria species and "inland terrestrial lichens" the other lichens isolated from Austria.

The alpha diversity of the non-cyanobacteria bacterial communities associated with the marine and maritime lichens and in the adjacent seawater was compared using different species diversity and richness indices calculated with a rarefied OTU table (Fig. 2). The marine and maritime lichens showed a significantly lower diversity than the inland terrestrial lichens $\left(t_{33}=3.35, p=0.001\right.$ for Inverse Simpson). L. pygmaea bacterial communities exhibited higher species richness than those of $L$. confinis (observed OTUs and ACE) but showed lower diversity as indicated by the Shannon and Inverse Simpson diversity metrics.

The taxonomic diversity at the phylum level of the non-cyanobacteria bacteria associated with the different lichens is shown in Fig. 3. Bacteroidetes and Proteobacteria were the dominant phyla in the marine and maritime lichens although the Lichina lichens showed a higher relative abundance of Bacteroidetes ( $>50 \%$ of the sequences) and Chloroflexi compared to the Xanthoria species. The two chlorolichen Xanthoria species collected from either the Mediterranean Sea or Atlantic Ocean coastlines were also associated with the candidate phylum FBP that was either absent or associated at very low abundance in the Lichina spp. Interestingly, the phylum Thermi comprising many

317 thermophilic species were predominantly associated with the Lichina and Xanthoria 318 lichens.

A comparison of the lichen bacterial community beta diversity as assessed by BrayCurtis dissimilarity of a rarefied OTU table and hierarchical clustering is shown in Fig 4A. 
321 The dendrogram shows a clear separation of the marine cyanolichens from the seawater

322 samples and also from the maritime lichens whose bacterial communities formed a 323 separate cluster with the inland terrestrial cyanolichens. The data was then reanalysed,

324 focusing on the most abundant OTUs associated with the lichens. This involved removing 325 the seawater samples from the dataset and filtering out low variance OTUs thus reducing 326 the OTU number from 2519 to 367 . Despite this filtering step, the clustering of the lichen 327 communities of the reduced dataset (Fig S2) was similar to that of the full dataset (Fig $3284 \mathrm{~A}$ ). ANOSIM tests confirmed that the separation of marine versus the other lichen 329 groups, and also the separation of the L. confinis and L. pygmaea groups was highly 330 significant $(R=1, p=0.001$ for both tests). The diversity of the bacterial communities in 331 the replicate samples of the maritime chlorolichens $X$. aureola and $X$. parietina clustered 332 according to sampling location (Atlantic Ocean or Mediterranean Sea coast).

333 At the OTU level, the marine versus the maritime-inland terrestrial lichens were 334 associated with very different bacterial communities as illustrated in Fig. 4B, which shows 335 the 30 most abundant OTUs for either group. The closest relatives of the OTU 336 representative sequences assessed by blasth are presented in Table S4. Over $80 \%$ of 337 the representative OTU sequences showed $>97 \%$ identity hits to previously deposited 338 sequences. OTUs with a lower \% identity belonged mainly to the Bacteroidetes phylum. 339 Interestingly, one Chloroflexi OTU (OTU_12) that was recovered from L. confinis showed 340 only a very low $91 \%$ identity to its closest previously described relative (Table S4) and 341 half of the closest relatives for the marine lichen OTUs originated from marine intertidal 342 outcrops (Couradeau et al., 2017).

343 A gammaproteobacterial OTU dominated in L. pygmaea and although this OTU was also 344 present in L. confinis, it was not the most abundant. L. confinis showed a more even 345 distribution of the OTUs compared to $L$. pygmaea as reflected by the diversity metrics. 346 Despite the relative spatial proximity of $X$. aureola and the Lichina lichens on the Atlantic 347 coast, there were very few shared OTUs among those genera. One OTU affiliated to the 348 candidate phylum FBP was present at low abundance in L. confinis and Xanthoria sp. but 349 not in L. pygmaea. The microbial communities recovered from the L. pygmaea samples 350 also showed very few OTUs in common with the seawater that was sampled in proximity 
351 to this lichen. This suggests that the L. pygmaea communities were specifically

352 associated to the lichen and very different from the free-living seawater communities.

353 Interestingly the Lichina lichens were associated with several OTUs belonging to the 354 Rhodothermaceae family (Bacteroidetes) and the Deinococcus-Thermus and Chloroflexi 355 phyla of which some members are meso- or thermophilic, highly resistant to UV radiation 356 (Deinococcus) and phototrophic (Chloroflexi). Although the Lichina communities showed 357 a similar genus-level composition with closely related OTUs (eg Lewinella, 358 Tunicatimonas, Rubricoccus) present in both lichens, these OTUs often showed an 359 inverse pattern of abundance between the two species, where OTUs in genera present 360 in both species tended to have higher counts in only one of the species (Figure 4).

Phylogenetic analysis has already been used to show that environmental filtering 362 rather than competitive effects structure marine bacterial communities (Pontarp et al., 363 2012). Similarly, to examine the potential ecological processes that could have influenced the community structure of the non-cyanobacteria bacteria in association with the lichen species, the level of phylogenetic clustering (indicative of environmental filtering) or overdispersion (competitive effects) was estimated from a calculation of the Net Relatedness Index (NRI) and the Nearest Taxon Index (NTI; (Webb, Ackerly \& Kembel, 2008). With the exception of the NRI for communities associated with L. confinis, there was evidence of phylogenetic clustering of the bacterial OTUs for the marine and maritime lichens as observed by a positive NRI and NTI (Table 2).

\section{Shared and specific bacterial OTUs in the marine and maritime lichens}

To explore the degree of overlap between the marine and maritime lichen bacterial communities in more detail, the OTUs consistently shared between the species, and potentially indicative of a core microbiome were identified (subsequently referred to as core OTUs). These OTUs were grouped at the family (or order when identification not possible) level and represented as relative abundance (Fig 5). Setting a very conservative threshold of $100 \%$ presence in all replicates of the marine lichen species, only 33 OTUs were shared by both species (Fig 5A). Of these, 15 were attributed to the Bacteroidetes families Saprospiraceae, Flammeovirgaceae and Rhodothermaceae (genera Lewinella, 
382 of the sequences amongst the core OTUs and showed similar relative abundances 383 between the two Lichina species (Fig 5A). Other families included the Chloroflexi 384 Caldilineaceae, and the Alphaproteobacteria families Rhodobacteraceae and 385 Erythrobacteraceae that were more abundant in L. confinis, and a Gammaproteobacteria 386 OTU in L. pygmaea.

387 When considering OTUs associated to each lichen species, 38 and 42 OTUs were 388 specific (i.e. present at $100 \%$ of the replicates) for L. confinis and L. pygmaea 389 respectively, and their relative abundances are shown in Fig $5 \mathrm{~B}$ and $5 \mathrm{C}$, grouped at the 390 family (or order when identification was not possible at the family level) level. The 391 distribution and relative abundance of the family level was very different between the two 392 species. For $L$. confinis, the most noticeable differences included a higher relative 393 abundance of Acidobacteria Ellin6075, Bacteroidetes Cytophagaceae and 394 Flammeovirgaceae and the Chloroflexi order Rosiflexales. For L. pygmaea, the 395 Actinobacteria family Euzebyaceae, and the Bacteroidetes families Saprospiraceae and 396 Flavobacteriaceae dominated the specific core OTUs.

397 To determine the OTUs that showed statistically significant differential abundances 398 between $L$. confinis and L. pygmaea, we used the DESeq2 negative binomial Wald test 399 (Love, Huber \& Anders, 2014). One third of the OTUs tested (120 out of 367 OTUs) 400 showed a significantly different distribution between the two lichens $(P<0.001)$ and those 401 OTUs with a mean abundance $>20$ are shown in Fig 6. These OTUs were distributed in 402 several shared families (left side of the plot) but we also observed differentially distributed 403 OTUs that were distinct for each lichen. Interestingly, 29 out of the 33 core Lichina OTUs 404 showed a statistically significant different distribution between the two species.

$405 X$. aureola collected above $L$. confinis on the littoral belt only shared one core OTU 406 with the Lichina lichens that was assigned to the Gammaproteobacteria OTU, the most 407 abundant OTU in L. pygmaea. $X$. aureola and $X$. parietina sampled from the Atlantic or 408 Mediterranean French coasts shared 24 core OTUs (Fig S3) that were dominated by the 409 Proteobacteria (mostly Alpha- and Betaproteobacteria) accounting for over $50 \%$ of the 410 sequences for each species. X. parietina, collected from the dryer Mediterranean coast, 411 showed higher relative abundances of Acidobacteria and the family Acetobacteraceae 412 (Alphaproteobacteria) compared to X. aureola. 


\section{Inland terrestrial cyanolichen-associated bacterial communities}

414 Out of the four inland terrestrial lichen species, L. auriforme and S. lichenoides showed 415 the highest diversity and species richness, followed by L. cristatum and L. fuscovirens 416 (Fig 2). As observed in previous surveys of terrestrial lichen bacterial diversity, these 417 inland lichen species were also dominated by the phylum Proteobacteria, attributed 418 mainly to the class Alphaproteobacteria (Fig 3). The phylum distributions were generally 419 similar amongst these species except the Bacteroidetes were almost twice as abundant 420 in L. cristatum and L. fuscovirens, compared to the abundance in the other two species.

421 The Bray-Curtis dissimilarity dendrogram (Fig 4A) shows that the bacterial 422 communities associated with $L$. auriforme were closely related to those of $S$. lichenoides 423 (both species were from the humid forest gorge) and this was confirmed with an ANOSIM 424 test that showed no significant difference between the species groups $(R=0.239, p=$ 425 0.064). The other two species $L$. cristatum and $L$. fuscovirens from the dryer, rocky zone 426 clustered apart and the separation of these two groups (humid forest versus dry/exposed) 427 was also significant $(R=0.582, p=0.017)$.

428 At the OTU level, the genus Sphingomonas (Alphaproteobacteria) was highly 429 represented in the maritime and inland terrestrial lichens and remarkably absent in the 430 marine lichens. Other OTUs present in all the inland terrestrial species included two OTUs 431 assigned to the order Rhizobiales, a Betaproteobacteria OTU assigned as Methylibium, 432 an Acidobacteria OTU and two Bacteroidetes OTUs belonging to the Chitinophagaceae. 433 For the inland terrestrial lichens, significant NRI values were only observed for $S$. 434 lichenoides and $L$. auriforme but none of these lichens showed significant phylogenetic 435 clustering at the tree tips for the NTI (Table 2).

Comparison of culturable species and total bacterial diversity from coastal lichens and $L$. auriforme

439 The 16S rRNA gene sequences of previously isolated strains originating from $L$. confinis, 440 L. pygmaea, and $L$. auriforme were compared to the sequences in this study to investigate 441 the representation of the culturable fraction relative to the bacterial diversity assessed by 442 the cultivation-independent molecular method. Thirty-four strains out of the 254 previously 443 isolated strains had 16 S rRNA sequence identities $>97 \%$ to the OTUs identified in this 
444 study (Table S5). The majority of the OTUs that had 16S rRNA sequences with high 445 identity $(>99 \%)$ to the strains were of low abundance $(<0.5 \%$ of total sequences) in our 446 study. One exception included the abundant OTU_37 (Sphingomonas; $\sim 4-14 \%$ of total 447 sequences) that shared $99 \%$ identity to a strain isolated from $L$. auriforme. One of the top 44830 most abundant OTUs from the marine lichens (OTU_21, Erythrobacteraceae) shared $44998 \%$ sequence identity with a strain isolated from L. pygmaea.

450

451

452

453

454

455

456

457

458

459

460

461

462

463

464

465

466

467

468

469

470

471

472

473

474

\section{Diversity of lichen photobionts and non-photobiont cyanobacteria}

The major photobiont of each of the cyanolichens was identified as the cyanobacterial OTU with the highest relative abundance among all the cyanobacterial sequences, and these identifications were confirmed with that reported in the literature (Otálora et al., 2010; Ortiz-Álvarez et al., 2015). The marine and inland terrestrial cyanolichens were associated with a different major photobiont. For $L$. confinis and $L$. pygmaea, the majority of the cyanobacterial reads clustered into a single Rivularia sp. OTU accounting for 51$82 \%$ of the reads for the $L$. confinis replicate samples and $25-79 \%$ for those of $L$. pygmaea. The remaining cyanobacterial sequences belonged principally to the order Chroococcales (including the family Xenococcaceae and the genus Chroococcidiopsis) and the family Pseudanabaenaceae (Fig S4). For the inland terrestrial lichens, two abundant Nostoc OTUs were identified. The first OTU was attributed as the primary photobiont in $L$. auriforme, L. cristatum and $L$. fuscovirens, accounting for $92-98 \%$ of all cyanobacterial sequences and was also present (albeit at less than $5.5 \%$ of all cyanobacterial sequences) in S. lichenoides. The second Nostoc OTU was the major photobiont of $S$. lichenoides, accounting for $92-94 \%$ of total cyanobacterial sequences in four out of five replicates ( $67 \%$ in the fifth) but had a low abundance in the other terrestrial lichens (at less than 0.5\%). Therefore, in contrast to the marine lichens, the inland terrestrial lichen photobionts dominated the cyanobacterial sequences. The nonphotobiont OTUs of these lichens included, amongst others, the genus Calothrix and members of the Chroococcales and together they did not exceed $10 \%$ of the total cyanobacterial sequences (Fig S4). As to be expected for chlorolichens, few cyanobacterial sequences ( $<5 \%$ of total reads) were obtained for the Xanthoria lichens but one chloroplast OTU was abundant in both species. Although only assigned as far as 
475 the order Chlorophyta, this OTU most likely represents the major photobiont of Xanthoria 476 which is known to be the green alga Trebouxia.

477

478

479

480

481

482

483

484

485 
486

487

488

489

490

491

492

493

494

495

496

497

498

499

500

501

502

503

504

505

506

507

508

509

510

511

512

513

514 515 (Hays et al., 2015).

\section{Discussion}

To date the largest body of lichen research has been undeniably devoted to terrestrial species. We address this knowledge gap in applying for the first time, next generation Illumina sequencing to characterise the bacterial communities associated to strict marine cyanolichens and a maritime chlorolichen, occupying different areas of the littoral zone. Whereas the two marine Lichina species, occurring in two neighbouring zones, share some common OTUs, many are specific to each species and there was very little overlap between the marine and maritime lichen bacterial communities.

\section{Lichina bacterial communities}

A comparison of the Lichina bacterial community diversity allowed us to identify potential core OTUs and specific OTUs for each species, reflecting the potential adaptation of $L$. confinis or $L$. pygmaea to their different littoral zones. The Lichina bacterial communities shared 15 of 33 core OTUs that were attributed to only 3 Bacteroidetes genera, Rubricoccus, Lewinella, and Tunicatimonas, as well as several Alphaproteobacteria OTUs from the Erythrobacteraceae and Rhodobacteraceae families, and a Chloroflexi OTU. Tunicatimonas pelagia which belongs to the Flammeovirgaceae family was initially isolated from a sea anemone (Yoon et al., 2012) and other members of this family are known to associate with corals (Apprill, Weber \& Santoro, 2016). Lewinella belongs to the Saprospiraceae family that was found as an epiphyte of red algae (Miranda et al., 2013) and on filamentous bacteria identified as Chloroflexi (Xia et al., 2008), and isolates from this genus were also cultured from marine lichens (Sigurbjornsdottir et al., 2014; Parrot et al., 2015). Notably, the bacterial groups associated with the Lichina lichens were also similar to those found in the surface layer of hypersaline microbial mats (Schneider et al., 2013) and in epiphytic communities on the red macroalga Porphyra umbilicalis (Miranda et al., 2013). The co-occurrence of these different bacteria in microbial mats and on various marine hosts suggests that they have adapted to similar environmental conditions. In functioning as a consortium, these communities could potentially increase their robustness and that of their hosts by expanding their range of metabolic capacities and resistance mechanisms to stress 
516 Interestingly there were multiple Lewinella, Tunicatimonas and Rubricoccus OTUs in 517 each lichen species and OTUs that were affiliated to the same genus were differentially 518 distributed between the two Lichina species (e.g., see the Lewinella OTUs 6, 7, 24 and 51961 in Fig 4). This could suggest that these bacterial genera belong to ecologically 520 differentiated pools as was already shown for the for the Rivularia cyanobionts of the 521 same lichen species (Ortiz-Álvarez et al., 2015). This mechanism of niche adaptation is 522 thought to occur in extreme environments and could also apply to the bacteria associated 523 to these marine lichens, which became adapted to the intertidal or supratidal zones. The 524 presence of these closely related clusters was also supported by the positive and 525 significant NTI values (Webb et al., 2002) indicative of environmental filtering effects on 526 the Lichina bacterial communities.

527 Rocky tidal zones are thought to be one of the most stressful habitats on earth (Miller, 528 Harley \& Denny, 2009) and both marine lichen species bacterial communities were 529 associated with several groups of bacteria that are known to be heat- or radiation530 resistant. These include several OTUs identified as core OTUs that were affiliated to the 531 genus Rubricoccus of the Rhodothermaceae (Park et al., 2011), to the phylum Chloroflexi 532 (that contains moderately thermophilic/thermophilic groups), and to the family 533 Truperaceae in which the isolated species are thermophilic and nearly as radiation 534 resistant as Deinococcus (Albuquerque et al., 2005).

535 Despite sharing 33 core OTUs, the two marine Lichina species $L$. confinis and $L$. 536 pygmaea were associated with significantly different bacterial communities at the OTU 537 level and remarkably the Bray Curtis dissimilarity distance between these communities 538 was greater than that of the distance between the communities associated with two 539 different inland terrestrial cyanolichen genera, Lathagrium auriforme and Scytinium 540 lichenoides (Fig 4A). This difference was also reflected in the high number of OTUs 541 (>120) that displayed a significantly different abundance between the two species (Fig 6). 542 These significant differences were despite the relatively short distance that separated the 543 species on the vertical gradient (height on the littoral belt). Other studies show evidence 544 that height on the littoral zone is the most important factor explaining the rocky coastline 545 species variance with slope, exposure, substrate and orientation explaining less 546 (Chappuis et al., 2014). L. confinis occurs higher up on the littoral belt, being mostly 
547 exposed to the air and would be subject to higher temperatures and UV radiation. This

548 could explain why some thermophilic groups such as Chloroflexi and the Actinobacterial 549 genus Rubrobacter that include thermophilic species resistant to radiation (Ferreira et al., 550 1999) were four-fold and 13 -fold respectively more abundant in $L$. confinis than $L$. 551 pygmaea. The bacterial groups that were more abundant in L. pygmaea when compared 552 to $L$. confinis included the Gammaproteobacteria OTU related to a seagrass epiphyte 553 Granulosicoccus (Kurilenko et al., 2010) an OTU affiliated to the Actinobacterial genus 554 Euzebya, recovered from a sea cucumber (Kurahashi et al., 2010) and several 555 Flavobacteriaceae and Rhodobacteraceae OTUs. Marine epiphytic Actinobacteria, and 556 Phaeobacter (Rhodobacteraceae), associated with a variety of marine plants and 557 animals, are known to produce bioactive molecules (Rao et al., 2007; Valliappan, Sun \& $558 \mathrm{Li}, 2014)$. Such molecules have been shown to inhibit settlement of algal spores, fungi 559 and larvae and may contribute to the host's defence against biofouling (Rao et al., 2007). 560 As $L$. pygmaea is immersed for half the day, it may be more subject to biofouling than $L$. 561 confinis and hence the biofilm communities covering the L. pygmaea may play an 562 important role in the inhibition of attachment of undesirable organisms.

563 Despite the significantly different bacterial communities observed in the two vertically 564 segregated Lichina species in the littoral belt, we did not find clear evidence for significant 565 differences between the samples of each species across horizontal distances (minimum $5666 \mathrm{~m}$ and maximum $37 \mathrm{~m}$ between clusters). This was indicated by beta-diversity analyses 567 both on the whole or filtered dataset which included the most abundant OTUs and which 568 revealed a lack of clustering of the replicates according to site. A lack of geographical 569 influence on the lichen associated bacterial communities was also observed in other 570 studies where sampling was carried out on a small spatial scale (Grube et al., 2009; Bates 571 et al., 2011). In a study where lichen sampling was carried out at a much greater spatial 572 scale, across the North American continent, a significant effect of geographical location 573 on bacterial communities associated with a specific species was observed (Hodkinson et 574 al., 2012).

\section{Low culturability of marine lichen associated bacteria}

576 Culturing of bacterial isolates from novel environments is essential for natural product 577 discovery. The harsh environments, in which the Lichina lichen species are found, could 
578 provide a wealth of bioactive products, particularly from the potentially 579 thermophilic/radiation resistant bacteria identified in our study. However, only 34 OTUs 580 showed significant similarity to the 254 previously isolated cultured isolates (Parrot et al., 5812015 ) even when lowering the similarity threshold to $97 \%$. Moreover, 3 OTUs that were $582100 \%$ identical to isolates were present at low abundances in the Illumina dataset. 583 Whereas the Bacteroidetes phylum accounted for around $53 \%$ of the $16 \mathrm{~S}$ rRNA 584 sequences from the marine lichens, only 4 strains from this phylum were cultured. These 585 results can be partly explained by the culturing strategy which was intentionally skewed 586 towards the isolation of Actinobacteria by using Actinobacteria Isolation Agar (Parrot et 587 al., 2015). As the bacterial isolates were obtained from lichens sampled 12-18 months 588 prior to those that were analysed in this study (even though they were collected from the 589 same site), we cannot rule out the influence of different sampling times on the bacterial 590 composition. Nevertheless, the low culturability of bacteria from certain environments is

591

592

593

594

595

596

597

598

599

600

601

602

603

604

605

606

607

608

well known (Amann, Ludwig \& Schleifer, 1995) and our results further highlight the importance of parallel culture independent molecular methods to gain a more complete picture of the microbial diversity. Such results, combined with metagenomic approaches to target gene clusters of interest (Vester, Glaring \& Stougaard, 2015) and novel isolation strategies incorporating lichen extracts into culture media (Biosca et al., 2016) should improve the bioprospecting of marine lichens. Nevertheless, the fact that some of the previously cultured strains were relatively close to the community described by our study, suggests that some of the bacteria associated with lichens might not be as recalcitrant to culture when compared to bacteria from other environments, highlighting the interest of these associations as sources of cultured microbial diversity.

Marine versus terrestrial lichens: challenging the paradigm of Alphaproteobacterial dominance

Here we show that bacterial communities in two strictly marine lichen species were completely different from those of two maritime and 4 inland terrestrial lichen species and that this difference is immediately visible at the phylum level with $50 \%$ of the sequences assigned to Bacteroidetes in Lichina, with a lower proportion of Proteobacteria (20-30\%), the converse of the inland lichens from the humid wooded zone (15-19\% Bacteroidetes and $50 \%$ Proteobacteria). At the OTU level, the differences were even more marked, with 
609 no overlap between the marine and inland terrestrial cyanolichens studied. The $X$. aureola 610 communities (sampled above L. confinis on the rocky shore) only shared a single OTU 611 with the Lichina lichens (Gammaproteobacteria OTU_15) which was only present at low 612 abundance $(0.05 \%)$. High abundances of Bacteroidetes were also observed in a different 613 marine lichen Hydropunctaria maura (Bjelland et al., 2011) and supports the idea that this 614 group of bacteria are major components of the bacterial communities associated with 615 marine lichens, whereas Alphaproteobacteria are well confirmed by several studies as 616 the dominant group associated with terrestrial lichens (Cardinale et al., 2008; Grube et 617 al., 2009b; Bates et al., 2011; Mushegian et al., 2011; Hodkinson et al., 2012). The marine 618 and the maritime/inland terrestrial lichen mycobionts did belong to two different classes 619 (Lichinomycetes and Lecanoromycetes respectively; see Table 1) so we cannot rule out 620 that this significant mycobiont taxonomic separation could be partly responsible for the 621 difference in bacterial community composition observed. Nevertheless, a survey of 622 bacterial communities associated with different cyanolichens and chlorolichens showed 623 that taxonomic dissimilarity of the mycobiont did not necessarily correlate with bacterial 624 community dissimilarity (Hodkinson et al., 2012). In that study, although Dictyonema 625 belongs to the division Basidiomycota while the other lichens belonged to the 626 Ascomycota, the bacterial communities of Dictyonema were still composed of $>50 \%$ 627 Alphaproteobacteria distributed into the same four orders as for the majority of the other 628 lichens. To be able to separate more clearly the influences of lichen taxonomy and habitat 629 on the diversity of the associated bacterial symbionts, ideally, a terrestrial Lichina lichen 630 species or another lichen belonging to the Lichinaceae family should be characterised in 631 the future.

632 In marine environments Bacteroidetes are specialised in degrading polymeric organic 633 matter and are adapted for an attached lifestyle by the production of adhesion proteins 634 (Fernández-Gómez et al., 2013). Although Bacteroidetes are often reported attached to 635 particles they are also known to be epiphytic on a variety of marine algae from temperate 636 regions and often co-occur with Proteobacteria (Lachnit et al., 2011; Burke et al., 2011; 637 Wahl et al., 2012; Miranda et al., 2013). Although high abundances of 638 Alphaproteobacteria sequences were detected on the green alga Ulva australis from 639 Botany Bay NSW Australia (Burke et al., 2011), Bacteroidetes was the most abundant 
640 group associated with the red alga Porphyra umbilicalis (Miranda et al., 2013) in Maine, 641 US and with red and brown algae sampled during summer months in Kiel Bight, Germany 642 (Lachnit et al., 2011). This suggests that Bacteroidetes may be important members of 643 marine epiphytic and perhaps epilichenic communities, although this would need to be 644 confirmed by microscopy-based (FISH) approaches.

645 Other differences between the marine and inland terrestrial lichens included the 646 relative abundance of the bacterial (non-cyanobacterial) sequences compared to the 647 cyanobacterial sequences that were as low as $20 \%$ in L. auriforme but accounted for 50 $64860 \%$ in the marine lichens (Fig S1). The marine lichen $H$. maura also had a higher 649 estimated concentration of bacterial cells in the lichen thallus compared to inland lichens 650 (Bjelland et al., 2011). These observations suggest that bacteria associated with marine 651 lichens might play a greater role in the functioning of the lichen symbiosis but this would 652 need to be confirmed by microscopy analyses and for example, metabolite profiling.

653 Several roles of lichen-associated bacteria have been suggested and include nutrient 654 supply (e.g. by nitrogen fixation and phosphate scavenging), nutrient recycling, protection 655 against UV radiation, resistance to abiotic and biotic environmental stressors, and thallus 656 degradation (Eymann et al., 2017). Unlike terrestrial lichens, marine lichens would need 657 to be adapted to much more variable gradients of UV light, salinity (osmotic) stress, heat, 658 desiccation and mechanical stresses from wave action and therefore we would expect 659 the associated bacteria to play a role in resisting these particularly variable conditions. 660 Although marine lichens can provide their own UV protection by the production of a 661 parietin derivative in the case of Xanthoria and mycosporine-like amino acids in the case 662 of the Lichina sp. (Roullier et al 2011), it is possible that the bacteria that colonise the 663 surface of the lichen like a biofilm (Cardinale et al., 2012b) could provide a protective 664 layer conferred by other photoprotective pigments. The majority of the identified OTUs 665 were affiliated to pigmented bacterial families, and several potentially phototrophic 666 bacterial groups such as the aerobic anoxygenic phototropic (AAP; e.g. Chloroflexi, 667 Erythrobacteraceae, Rhodobacteraceae) or rhodopsin-containing bacteria (e.g. 668 Flavobacteriaceae, (Yoshizawa et al., 2014), Rhodothermaceae (Vavourakis et al., 669 2016), Deinococcus-Thermus) that contain carotenoids that may have a photoprotective 670 role. 
671 To alleviate salt stress and resist desiccation, marine lichens and their photobionts 672 accumulate compatible solutes that are mainly sugars, sugar alcohols and complex 673 sugars, lowering the water potential and hence reducing water movement out of the cells 674 (Delmail et al., 2013). Indeed L. pygmaea which is immersed in seawater for half the day 675 was shown to resist salt stress better than Xanthoria aureola, which is located higher up 676 on the littoral belt and only receives sea spray (Delmail et al., 2013). Marine biofilms are 677 considered to be analogous to a multicellular organism in that it functions like a "second 678 skin", replacing the hosts top layers as the new interface between the host and the 679 environment (Wahl et al., 2012). Such a function could be imagined for the bacteria 680 associated with L. pygmaea that could contribute to the osmotic adaptation of the lichen 681 by maintaining a layer of cells in osmotic balance with the surrounding water. This could 682 be achieved by different mechanisms including the synthesis and uptake of organic 683 osmolytes and by using a sodium pumping rhodopsin as inferred from Bacteroidetes 684 metagenomes recovered from hypersaline lakes (Vavourakis et al., 2016). While this is 685 speculative, bacterial communities inhabiting the rhizosphere of coastal plants were 686 shown to confer salt stress acclimatisation to the plants, potentially though the use of ion 687 and compatible solute transporters (Yuan et al., 2016).

In cyanolichens or tripartite lichens, fixed carbon and nitrogen are supplied to the 689 mycobiont by the photobiont whereas phosphate was shown to be a limiting 690 macronutrient since cyanolichen growth was stimulated after immersing the thalli in a 691 phosphate solution (McCune \& Caldwell, 2009). This was also supported by 692 metagenomic and proteomic analysis of two terrestrial lichens that attributed an important 693 role of phosphate solubiliation genes to the associated microbial community, more 694 specifically to the Alphaproteobacteria (Grube et al., 2015; Sigurbjornsdottir, Andresson 695 \& Vilhelmsson, 2015). The Lichina lichens may be less subject to phosphate limitation 696 because $L$. pygmaea is immersed in seawater for half a day and $L$. confinis receives sea 697 spray in a coastal area that is not particularly phosphorus limited. Nevertheless, some of 698 the associated bacteria may play a role in phosphate uptake from the seawater or in the 699 recycling and transfer of phosphate from senescing parts of the thallus to the growing 700 apices as was shown for Cladonia (Hyvärinen \& Crittenden, 2000). Such nutrient 701 recycling may be carried out in part by the Bacteroidetes that are known to produce a 
702 wide range of enzymes capable of degrading polymeric organic matter including

703 glycoside hydrolases and peptidases (Fernández-Gómez et al., 2013).

704

705 Conclusions

706 Here we show the striking differences between bacterial communities associated with 707 marine and terrestrial lichens and even between marine lichens inhabiting different littoral 708 zones. This represents a first piece in the puzzle in understanding the role of the 709 associated bacteria in the marine lichen symbiosis, which is lagging much behind that of 710 the terrestrial lichens. To begin to elucidate the functions of these communities, future 711 work should include a multidisciplinary approach combining microscopy techniques to 712 determine the spatial organisation of the core microbiome members and "omic" 713 approaches to understand their functional role. An integrative study using metagenomics, 714 metatranscriptomics and metabolomics could be performed on L. pygmaea during high 715 and low tide to reveal a wealth of information on how the symbiotic partners interact and 716 adapt to these extreme conditions. Moreover, such information would not only further our

717 understanding of the marine lichen symbiosis but could also guide future bioprospecting 718 efforts.

719

720

Acknowledgements

721 We thank the BIO2MAR platform (http://bio2mar.obs-banyuls.fr) for providing technical

722 support and access to instrumentation. The following reagent was obtained through BEI

723 Resources, NIAID, NIH as part of the Human Microbiome Project: Genomic DNA from

724 Microbial Mock Community B (Even, Low Concentration), v5.1L, for 16S rRNA Gene

725 Sequencing, HM-782D. We would also like to thank Dr. Nicolas Magain for his thorough

726 and thoughtful review, particularly on the lichen taxonomy, which greatly helped to

727 improve this paper. 


\section{References}

729 Albuquerque L., Simões C., Nobre MF., Pino NM., Battista JR., Silva MT., Rainey FA., da

730

731

732

733

734

735

736

737

738

739

740

741

742

743

744

745

746

747

748

749

750

751
Costa MS. 2005. Truepera radiovictrix gen. nov., sp. nov., a new radiation resistant species and the proposal of Trueperaceae fam. nov. FEMS Microbiology Letters 247:161-169. DOI: 10.1016/j.femsle.2005.05.002.

Altschul SF., Madden TL., Schaffer AA., Zhang J., Zhang Z., Miller W., Lipman DJ. 1997. Gapped BLAST and PSI-BLAST: A New Generation of Protein Database Search Programs. Nucleic Acids Research 25:3389-3402.

Amann RI., Ludwig W., Schleifer KH. 1995. Phylogenetic Identification and In Situ Detection Of Individual Microbial Cells Without Cultivation. Microbiological Reviews 59:143-169.

Apprill A., Weber LG., Santoro AE. 2016. Distinguishing between Microbial Habitats Unravels Ecological Complexity in Coral Microbiomes. mSystems 1. DOI: 10.1128/mSystems.00143-16.

Aschenbrenner IA., Cernava T., Berg G., Grube M. 2016. Understanding Microbial MultiSpecies Symbioses. Frontiers in Microbiology 7:180. DOI: 10.3389/fmicb.2016.00180.

Bates ST., Cropsey GWG., Caporaso JG., Knight R., Fierer N. 2011. Bacterial Communities Associated with the Lichen Symbiosis. Applied and Environmental Microbiology 77:1309-1314. DOI: 10.1128/AEM.02257-10.

Biosca EG., Flores R., Santander RD., Díez-Gil JL., Barreno E. 2016. Innovative Approaches Using Lichen Enriched Media to Improve Isolation and Culturability of Lichen Associated Bacteria. PLOS ONE 11. DOI: 10.1371/journal.pone.0160328.

Bjelland T., Grube M., Hoem S., Jorgensen SL., Daae FL., Thorseth IH., Ovreas L. 2011. Microbial metacommunities in the lichen-rock habitat. Environmental Microbiology Reports 3:434-442. DOI: 10.1111/j.1758-2229.2010.00206.x. 
752 Boustie J., Grube M. 2005. Lichens-a promising source of bioactive secondary metabolites.

753 Plant Genetic Resources 3:273-287. DOI: 10.1079/PGR200572.

754 Burke C., Thomas T., Lewis M., Steinberg P., Kjelleberg S. 2011. Composition, uniqueness and 755 variability of the epiphytic bacterial community of the green alga Ulva australis. The 756 ISME Journal 5:590-600. DOI: 10.1038/ismej.2010.164.

757 Caporaso JG., Kuczynski J., Stombaugh J., Bittinger K., Bushman FD., Costello EK., Fierer N., 758 Peña AG., Goodrich JK., Gordon JI., Huttley GA., Kelley ST., Knights D., Koenig JE., 759

760

761

762 Ley RE., Lozupone CA., McDonald D., Muegge BD., Pirrung M., Reeder J., Sevinsky JR., Turnbaugh PJ., Walters WA., Widmann J., Yatsunenko T., Zaneveld J., Knight R.

763 Cardinale M., de Castro JV., Mueller H., Berg G., Grube M. 2008. In situ analysis of the 764 765 2010. QIIME allows analysis of high-throughput community sequencing data. Nature Methods 7:335-336. DOI: 10.1038/nmeth.f.303. bacterial community associated with the reindeer lichen Cladonia arbuscula reveals predominance of Alphaproteobacteria. FEMS Microbiology Ecology 66:63-71. DOI:

766 10.1111/j.1574-6941.2008.00546.x.

767 Cardinale M., Grube M., Castro JV., Mueller H., Berg G. 2012a. Bacterial taxa associated with 768 769 the lung lichen Lobaria pulmonaria are differentially shaped by geography and habitat. FEMS Microbiology Letters 329:111-115. DOI: 10.1111/j.1574-6968.2012.02508.x.

770 Cardinale M., Puglia AM., Grube M. 2006. Molecular analysis of lichen-associated bacterial 771 772 communities. FEMS Microbiology Ecology 57:484-495. DOI: 10.1111/j.15746941.2006.00133.x. 
773 Cardinale M., Steinova J., Rabensteiner J., Berg G., Grube M. 2012b. Age, sun and substrate:

774 triggers of bacterial communities in lichens. Environmental Microbiology Reports 4:23-

775 28. DOI: $10.1111 / \mathrm{j} .1758-2229.2011 .00272 . x$.

776 Chappuis E., Terradas M., Cefalì ME., Mariani S., Ballesteros E. 2014. Vertical zonation is the

777 main distribution pattern of littoral assemblages on rocky shores at a regional scale.

778 Estuarine, Coastal and Shelf Science 147:113-122. DOI: 10.1016/j.ecss.2014.05.031.

779 Couradeau E., Roush D., Guida BS., Garcia-Pichel F. 2017. Diversity and mineral substrate

780 preference in endolithic microbial communities from marine intertidal outcrops (Isla de

781 Mona, Puerto Rico). Biogeosciences 14:311-324. DOI: 10.5194/bg-14-311-2017.

782 Delmail D., Grube M., Parrot D., Cook-Moreau J., Boustie J., Labrousse P., Tomasi S. 2013.

783 Halotolerance in Lichens: Symbiotic Coalition Against Salt Stress. In: Ahmad P, Azooz

784 MM, Prasad MNV eds. Ecophysiology and Responses of Plants under Salt Stress.

785 Springer New York, 115-148. DOI: 10.1007/978-1-4614-4747-4_4.

786 Edgar RC. 2013. UPARSE: highly accurate OTU sequences from microbial amplicon reads.

787 Nature Methods 10:996-998. DOI: 10.1038/nmeth.2604.

788 Edgar RC., Flyvbjerg H. 2015. Error filtering, pair assembly, and error correction for next-

789 generation sequencing reads. Bioinformatics:btv401. DOI:

$790 \quad$ 10.1093/bioinformatics/btv401.

791 Eilers H., Pernthaler J., Amann R. 2000. Succession of Pelagic Marine Bacteria during

792 Enrichment: a Close Look at Cultivation-Induced Shifts. Applied and Environmental

793 Microbiology 66:4634-4640.

794 Eymann C., Lassek C., Wegner U., Bernhardt J., Fritsch OA., Fuchs S., Otto A., Albrecht D.,

795 Schiefelbein U., Cernava T., Aschenbrenner I., Berg G., Grube M., Riedel K. 2017. 
796

797

798

799

800

801

802

803

804

805

806

807

808

809

810

811

812

813

814

815 Grube M., Cardinale M., de Castro JV., Müller H., Berg G. 2009. Species-specific structural and 816

817

Symbiotic Interplay of Fungi, Algae, and Bacteria within the Lung Lichen Lobaria pulmonaria L. Hoffm. as Assessed by State-of-the-Art Metaproteomics. Journal of Proteome Research 16:2160-2173. DOI: 10.1021/acs.jproteome.6b00974.

Faircloth BC., Glenn TC. 2012. Not All Sequence Tags Are Created Equal: Designing and Validating Sequence Identification Tags Robust to Indels. PLOS ONE 7:e42543. DOI: 10.1371/journal.pone.0042543.

Ferguson RL., Buckley EN., Palumbo AV. 1984. Response of marine bacterioplankton to differential filtration and confinement. Applied and Environmental Microbiology 47:4955.

Fernández-Gómez B., Richter M., Schüler M., Pinhassi J., Acinas SG., González JM., PedrósAlió C. 2013. Ecology of marine Bacteroidetes: a comparative genomics approach. The ISME Journal 7:1026-1037. DOI: 10.1038/ismej.2012.169.

Ferreira AC., Nobre MF., Moore E., Rainey FA., Battista JR., Costa MS da. 1999. Characterization and radiation resistance of new isolates of Rubrobacter radiotolerans and Rubrobacter xylanophilus. Extremophiles 3:235-238. DOI: 10.1007/s007920050121.

Fletcher A. 1973a. The Ecology of Marine (Littoral) Lichens on some Rocky shores of Anglesey. The Lichenologist 5:368-400. DOI: 10.1017/S0024282973000459.

Fletcher A. 1973b. The Ecology of Maritime (Supralittoral) Lichens on some Rocky Shores of Anglesey. The Lichenologist 5:401-422. DOI: 10.1017/S0024282973000460. functional diversity of bacterial communities in lichen symbioses. The ISME journal 3:1105-1115. DOI: $10.1038 /$ ismej.2009.63. 
818 Grube M., Cernava T., Soh J., Fuchs S., Aschenbrenner I., Lassek C., Wegner U., Becher D., 819 Riedel K., Sensen CW., Berg G. 2015. Exploring functional contexts of symbiotic sustain 820 within lichen-associated bacteria by comparative omics. The ISME journal 9:412-424. $821 \quad$ DOI: $10.1038 /$ ismej.2014.138.

822 Hays SG., Patrick WG., Ziesack M., Oxman N., Silver PA. 2015. Better together: engineering 823 and application of microbial symbioses. Current Opinion in Biotechnology 36:40-49.

824 DOI: 10.1016/j.copbio.2015.08.008.

825 Henkel PA., Yuzhakova L. 1936. Nitrogen-fixing bacteria in lichens. Izv. Biol. Inst. Permsk. 826 Gos. Univ. 10:9-10.

827 Hodkinson BP., Gottel NR., Schadt CW., Lutzoni F. 2012. Photoautotrophic symbiont and

828

829

830

831

832

833

834

835

836

837 Kembel SW., Cowan PD., Helmus MR., Cornwell WK., Morlon H., Ackerly DD., Blomberg 838

839 geography are major factors affecting highly structured and diverse bacterial communities in the lichen microbiome. Environmental Microbiology 14:147-161. DOI: 10.1111/j.1462-2920.2011.02560.x.

Honegger R., Edwards D., Axe L. 2013. The earliest records of internally stratified cyanobacterial and algal lichens from the Lower Devonian of the Welsh Borderland. The New Phytologist 197:264-275. DOI: 10.1111/nph.12009.

Hyvärinen M., Crittenden PD. 2000. 33P translocation in the thallus of the mat-forming lichen Cladonia portentosa. The New Phytologist 145:281-288. DOI: 10.1046/j.14698137.2000.00581.x. SP., Webb CO. 2010. Picante: R tools for integrating phylogenies and ecology. Bioinformatics (Oxford, England) 26:1463-1464. DOI: 10.1093/bioinformatics/btq166. 
840 Klindworth A., Pruesse E., Schweer T., Peplies J., Quast C., Horn M., Glöckner FO. 2012.

841 Evaluation of general 16S ribosomal RNA gene PCR primers for classical and next-

842 generation sequencing-based diversity studies. Nucleic Acids Research:gks808. DOI:

$843 \quad 10.1093 /$ nar/gks808.

844 Kranner I., Beckett R., Hochman A., Nash TH. 2008. Desiccation-Tolerance in Lichens: A

845 Review. The Bryologist 111:576-593. DOI: 10.1639/0007-2745-111.4.576.

846 Kurahashi M., Fukunaga Y., Sakiyama Y., Harayama S., Yokota A. 2010. Euzebya tangerina

847

848 gen. nov., sp. nov., a deeply branching marine actinobacterium isolated from the sea

849 cucumber Holothuria edulis, and proposal of Euzebyaceae fam. nov., Euzebyales ord.

850 nov. and Nitriliruptoridae subclassis nov. International Journal of Systematic and Evolutionary Microbiology 60:2314-2319. DOI: 10.1099/ijs.0.016543-0.

852

Kurilenko VV., Christen R., Zhukova NV., Kalinovskaya NI., Mikhailov VV., Crawford RJ.,

853 Ivanova EP. 2010. Granulosicoccus coccoides sp. nov., isolated from leaves of seagrass

854 (Zostera marina). International Journal of Systematic and Evolutionary Microbiology

855 60:972-976. DOI: 10.1099/ijs.0.013516-0. 856

Lachnit T., Meske D., Wahl M., Harder T., Schmitz R. 2011. Epibacterial community patterns on marine macroalgae are host-specific but temporally variable. Environmental

857 Microbiology 13:655-665. DOI: 10.1111/j.1462-2920.2010.02371.x. Ramos PL., Moreira-Filho CA., Barbosa HR. 2006. Nitrogen-fixing chemo860 organotrophic bacteria isolated from cyanobacteria-deprived lichens and their ability to solubilize phosphate and to release amino acids and phytohormones. Journal of Applied Microbiology 101:1076-1086. DOI: 10.1111/j.1365-2672.2006.03010.x. 
863 Love MI., Huber W., Anders S. 2014. Moderated estimation of fold change and dispersion for 864 RNA-seq data with DESeq2. Genome Biology 15:550. DOI: 10.1186/s13059-014-0550-8.

865 McCune B., Caldwell BA. 2009. A single phosphorus treatment doubles growth of 866 cyanobacterial lichen transplants. Ecology 90:567-570.

867 McMurdie PJ., Holmes S. 2013. phyloseq: An R Package for Reproducible Interactive Analysis 868 and Graphics of Microbiome Census Data. PLOS ONE 8:e61217. DOI:

869 10.1371/journal.pone.0061217.

870 Miller LP., Harley CDG., Denny MW. 2009. The role of temperature and desiccation stress in 871 limiting the local-scale distribution of the owl limpet, Lottia gigantea. Functional 872 Ecology 23:756-767. DOI: 10.1111/j.1365-2435.2009.01567.x.

873 Miranda LN., Hutchison K., Grossman AR., Brawley SH. 2013. Diversity and Abundance of the 874 Bacterial Community of the Red Macroalga Porphyra umbilicalis: Did Bacterial Farmers

875 Produce Macroalgae? PLOS ONE 8:e58269. DOI: 10.1371/journal.pone.0058269.

Mushegian AA., Peterson CN., Baker CCM., Pringle A. 2011. Bacterial Diversity across Individual Lichens. Applied and Environmental Microbiology 77:4249-4252. DOI:

878 10.1128/AEM.02850-10.

879 Myllys L., Lohtander K., Tehler A. 2001. $\beta$-Tubulin, ITS and Group I Intron Sequences 880 Challenge the Species Pair Concept in Physcia aipolia and P. caesia. Mycologia 93:335881 343. DOI: $10.2307 / 3761655$.

882 Oksanen J., Blanchet FG., Kindt R., Legendre P., Minchin P., O’Hara R., Simpson G., Solymos 883 P., Stevens M., Wagner H. 2013. Vegan: Community Ecology Package. R Package

884 Version. 2.0-10. CRAN. 
885 Ortiz-Álvarez R., de los Ríos A., Fernández-Mendoza F., Torralba-Burrial A., Pérez-Ortega S. 886 2015. Ecological Specialization of Two Photobiont-Specific Maritime Cyanolichen

887

888

889

890

891

892

893

894

895

896

897

898

899

900

901

902

903

904

905

906

907 Species of the Genus Lichina. PLOS ONE 10:e0132718. DOI: 10.1371/journal.pone.0132718.

Otálora MAG., Aragón G., Molina MC., Martínez I., Lutzoni F. 2010. Disentangling the Collema-Leptogium complex through a molecular phylogenetic study of the Collemataceae (Peltigerales, lichen-forming Ascomycota). Mycologia 102:279-290. DOI: $10.3852 / 09-114$.

Park S., Yoshizawa S., Kogure K., Yokota A. 2011. Rubricoccus marinus gen. nov., sp. nov., of the family "Rhodothermaceae", isolated from seawater. International Journal of Systematic and Evolutionary Microbiology 61:2069-2072. DOI: 10.1099/ijs.0.026294-0.

Parrot D., Antony-Babu S., Intertaglia L., Grube M., Tomasi S., Suzuki MT. 2015. Littoral lichens as a novel source of potentially bioactive Actinobacteria. Scientific Reports 5:15839. DOI: $10.1038 /$ srep 15839 .

Parrot D., Legrave N., Delmail D., Grube M., Suzuki M., Tomasi S. 2016. Review - LichenAssociated Bacteria as a Hot Spot of Chemodiversity: Focus on Uncialamycin, a Promising Compound for Future Medicinal Applications. Planta Medica 82:1143-1152. DOI: $10.1055 / \mathrm{s}-0042-105571$.

Pontarp M., Canbäck B., Tunlid A., Lundberg P. 2012. Phylogenetic analysis suggests that habitat filtering is structuring marine bacterial communities across the globe. Microbial Ecology 64:8-17. DOI: 10.1007/s00248-011-0005-7.

R. Core Team. 2015. R: A language and environment for statistical computing [Internet]. Vienna, Austria: R Foundation for Statistical Computing; 2014. 
908 Rao D., Webb JS., Holmström C., Case R., Low A., Steinberg P., Kjelleberg S. 2007. Low

909 Densities of Epiphytic Bacteria from the Marine Alga Ulva australis Inhibit Settlement of

$910 \quad$ Fouling Organisms. Applied and Environmental Microbiology 73:7844-7852. DOI:

$911 \quad$ 10.1128/AEM.01543-07.

912 Schloss PD., Westcott SL., Ryabin T., Hall JR., Hartmann M., Hollister EB., Lesniewski RA.,

913 Oakley BB., Parks DH., Robinson CJ., Sahl JW., Stres B., Thallinger GG., Van Horn DJ.,

914 Weber CF. 2009. Introducing mothur: open-source, platform-independent, community-

915 supported software for describing and comparing microbial communities. Applied and

916 Environmental Microbiology 75:7537-7541. DOI: 10.1128/AEM.01541-09.

917 Schneider D., Arp G., Reimer A., Reitner J., Daniel R. 2013. Phylogenetic Analysis of a

918 Microbialite-Forming Microbial Mat from a Hypersaline Lake of the Kiritimati Atoll,

919 Central Pacific. PLOS ONE 8:e66662. DOI: 10.1371/journal.pone.0066662.

920 Schultz M. 2017. Morphological and molecular data support Lichina intermedia as a distinct

921 austral-marine species in the L. pygmaea group. The Lichenologist 49:321-332. DOI:

$922 \quad 10.1017 / \mathrm{S} 0024282917000251$.

923 Sigurbjornsdottir MA., Andresson OS., Vilhelmsson O. 2015. Analysis of the Peltigera

924 membranacea metagenome indicates that lichen-associated bacteria are involved in

925 phosphate solubilization. Microbiology 161:989-996. DOI: 10.1099/mic.0.000069.

926 Sigurbjornsdottir MA., Heidmarsson S., Jonsdottir AR., Vilhelmsson O. 2014. Novel bacteria

927 associated with Arctic seashore lichens have potential roles in nutrient scavenging.

928 Canadian Journal of Microbiology 60:307-317. DOI: 10.1139/cjm-2013-0888. 
929 Suzuki MT., Parrot D., Berg G., Grube M., Tomasi S. 2016. Lichens as natural sources of 930 biotechnologically relevant bacteria. Applied Microbiology and Biotechnology 100:583595. DOI: 10.1007/s00253-015-7114-Z.

932 Valliappan K., Sun W., Li Z-Y. 2014. Marine actinobacteria associated with marine organisms and their potentials in producing pharmaceutical natural products. Applied Microbiology and Biotechnology 98. DOI: 10.1007/s00253-014-5954-6.

Vavourakis CD., Ghai R., Rodriguez-Valera F., Sorokin DY., Tringe SG., Hugenholtz P., Muyzer G. 2016. Metagenomic Insights into the Uncultured Diversity and Physiology of Microbes in Four Hypersaline Soda Lake Brines. Frontiers in Microbiology 7. DOI: 10.3389/fmicb.2016.00211.

Vester JK., Glaring MA., Stougaard P. 2015. Improved cultivation and metagenomics as new tools for bioprospecting in cold environments. Extremophiles 19:17-29. DOI: 10.1007/s00792-014-0704-3.

Vilgalys R., Hester M. 1990. Rapid genetic identification and mapping of enzymatically amplified ribosomal DNA from several Cryptococcus species. Journal of Bacteriology $172: 4238-4246$.

Wahl M., Goecke F., Labes A., Dobretsov S., Weinberger F. 2012. The Second Skin: Ecological 948 Webb C., Ackerly D., Kembel S. 2008. Phylocom: software for the analysis of phylogenetic 949 community structure and trait evolution. Bioinformatics 24:2098-2100. 
950 Webb CO., Ackerly DD., McPeek MA., Donoghue MJ. 2002. Phylogenies and Community

951 Ecology. Annual Review of Ecology and Systematics 33:475-505. DOI:

952 10.1146/annurev.ecolsys.33.010802.150448.

953 White T., Bruns T., Lee S., Taylor J. 1990. Amplification and direct sequencing of fungal

954

955

956

957

958

959

960

961

962

963

964

965

966

967

968

969

970

971

ribosomal RNA genes for phylogenetics. In: Innis M, Gelfand D, Shinsky J, White T eds. PCR Protocols: A Guide to Methods and Applications. Academic Press, 315-322.

Xia Y., Kong Y., Thomsen TR., Halkjær Nielsen P. 2008. Identification and Ecophysiological Characterization of Epiphytic Protein-Hydrolyzing Saprospiraceae ("Candidatus Epiflobacter" spp.) in Activated Sludge. Applied and Environmental Microbiology 74:2229-2238. DOI: 10.1128/AEM.02502-07.

Yoon J., Oku N., Park S., Katsuta A., Kasai H. 2012. Tunicatimonas pelagia gen. nov., sp. nov., a novel representative of the family Flammeovirgaceae isolated from a sea anemone by the differential growth screening method. Antonie Van Leeuwenhoek 101:133-140. DOI: 10.1007/s10482-011-9626-6.

Yoshizawa S., Kumagai Y., Kim H., Ogura Y., Hayashi T., Iwasaki W., DeLong EF., Kogure K. 2014. Functional characterization of flavobacteria rhodopsins reveals a unique class of light-driven chloride pump in bacteria. Proceedings of the National Academy of Sciences 111:6732-6737. DOI: 10.1073/pnas.1403051111.

Yuan Z., Druzhinina IS., Labbé J., Redman R., Qin Y., Rodriguez R., Zhang C., Tuskan GA., Lin F. 2016. Specialized Microbiome of a Halophyte and its Role in Helping Non-Host Plants to Withstand Salinity. Scientific Reports 6:32467. DOI: 10.1038/srep32467. 


\section{Table $\mathbf{1}$ (on next page)}

Lichen species analysed in this study

The different lichen species sampled in this study are presented with details on their corresponding mycobiont and photobiont partners, their habitat and the location of the sampling sites. 
1 Table 1. Lichen species analysed in this study

2

\begin{tabular}{|l|l|l|l|l|l|}
\hline $\begin{array}{l}\text { Lichen } \\
\text { species }\end{array}$ & Mycobiont & Photobiont & Habitat & Date & Location \\
\hline $\begin{array}{l}\text { Lichina } \\
\text { confinis }\end{array}$ & $\begin{array}{l}\text { Lichinomycetes, } \\
\text { Lichinales, } \\
\text { Lichinaceae }\end{array}$ & $\begin{array}{l}\text { Cyanobacteria: } \\
\text { Rivularia sp }\end{array}$ & $\begin{array}{l}\text { Upper } \\
\text { eulittoral }\end{array}$ & 16.10 .13 & $\begin{array}{l}\text { Erquy, France } \\
\text { (Atlantic Ocean) }\end{array}$ \\
\hline $\begin{array}{l}\text { Lichina } \\
\text { pygmaea }\end{array}$ & $\begin{array}{l}\text { Lichinomycetes, } \\
\text { Lichinales, } \\
\text { Lichinaceae }\end{array}$ & $\begin{array}{l}\text { Cyanobacteria: } \\
\text { Rivularia sp }\end{array}$ & $\begin{array}{l}\text { Lower } \\
\text { eulittoral }\end{array}$ & 16.10 .13 & $\begin{array}{l}\text { Erquy, France } \\
\text { (Atlantic Ocean) }\end{array}$ \\
\hline $\begin{array}{l}\text { Xanthoria } \\
\text { aureola }\end{array}$ & $\begin{array}{l}\text { Lecanoromycetes, } \\
\text { Teloschistales, } \\
\text { Teloschistaceae }\end{array}$ & $\begin{array}{l}\text { Green alga: } \\
\text { Trebouxia sp }\end{array}$ & $\begin{array}{l}\text { Mesic- } \\
\text { supralittoral }\end{array}$ & 16.10 .13 & $\begin{array}{l}\text { Erquy, France } \\
\text { (Atlantic Ocean) }\end{array}$ \\
\hline $\begin{array}{l}\text { Xanthoria } \\
\text { parietina }\end{array}$ & $\begin{array}{l}\text { Lecanoromycetes, } \\
\text { Teloschistales, } \\
\text { Teloschistaceae }\end{array}$ & $\begin{array}{l}\text { Green alga: } \\
\text { Trebouxia sp }\end{array}$ & $\begin{array}{l}\text { Xeric- } \\
\text { supralittoral }\end{array}$ & 06.03 .14 & $\begin{array}{l}\text { Banyuls sur mer, } \\
\text { France } \\
\text { (Mediterranean } \\
\text { Sea) }\end{array}$ \\
\hline $\begin{array}{l}\text { Lathagrium } \\
\text { auriforme }\end{array}$ & $\begin{array}{l}\text { Lecanoromycetes, } \\
\text { Peltigerales } \\
\text { Collemataceae }\end{array}$ & $\begin{array}{l}\text { Cyanobacteria: } \\
\text { Nostoc sp. }\end{array}$ & Terrestrial & 26.11 .13 & $\begin{array}{l}\text { Kesselfalklamm, } \\
\text { Austria }\end{array}$ \\
\hline $\begin{array}{l}\text { Lathagrium } \\
\text { cristatum }\end{array}$ & $\begin{array}{l}\text { Lecanoromycetes, } \\
\text { Peltigerales } \\
\text { Collemataceae }\end{array}$ & $\begin{array}{l}\text { Cyanobacteria: } \\
\text { Nostoc sp. }\end{array}$ & Terrestrial & 26.11 .13 & $\begin{array}{l}\text { Kesselfalklamm, } \\
\text { Austria }\end{array}$ \\
\hline $\begin{array}{l}\text { Lathagrium } \\
\text { fuscovirens }\end{array}$ & $\begin{array}{l}\text { Lecanoromycetes, } \\
\text { Peltigerales } \\
\text { Collemataceae }\end{array}$ & $\begin{array}{l}\text { Cyanobacteria: } \\
\text { Nostoc sp. }\end{array}$ & Terrestrial & 26.11 .13 & $\begin{array}{l}\text { Kesselfalklamm, } \\
\text { Austria }\end{array}$ \\
\hline $\begin{array}{l}\text { Scytinium } \\
\text { lichenoides }\end{array}$ & $\begin{array}{l}\text { Lecanoromycetes, } \\
\text { Peltigerales } \\
\text { Collemataceae }\end{array}$ & $\begin{array}{l}\text { Cyanobacteria: } \\
\text { Nostoc sp. }\end{array}$ & Terrestrial & 26.11 .13 & $\begin{array}{l}\text { Kesselfalklamm, } \\
\text { Austria }\end{array}$ \\
\hline
\end{tabular}

3 


\section{Table 2 (on next page)}

Levels of phylogenetic clustering of the lichen associated bacterial communities as measured by the Nearest Taxon Index (NTI) and the Net Relatedness Index (NRI).

The values of each metric for the coastal or inland lichens are presented together with the number of runs where the observed NRI/NTI values were greater than those of the null model. $* p<0.05, * * p<0.01$. 
1 Table 2. Levels of phylogenetic clustering of the lichen associated bacterial communities as

2 measured by the Nearest Taxon Index (NTI) and the Net Relatedness Index (NRI).

3

\begin{tabular}{|l|l|l|l|l|l|}
\hline Lichen species & $\mathbf{N}^{\circ}$ taxa & NRI & runs > null & NTI & runs > null \\
\hline Coastal Brittany lichens & 271 & 1.42 & 905 & $2.30^{* *}$ & 991 \\
\hline L. confinis & 281 & $3.49^{* *}$ & 998 & $1.68^{*}$ & 951 \\
\hline L. pygmaea & 281 & $9.13^{* *}$ & 997 & $2.15^{*}$ & 978 \\
\hline X. aureola & 224 & $2.15^{*}$ & 983 & 0.12 & 552 \\
\hline Inland Austrian lichens & $2.53^{* *}$ & 992 & 1.73 & 944 \\
\hline S. Lichenoides & 294 & 1.32 & 902 & 0.92 & 825 \\
\hline L. auriforme & 260 & 1.05 & 859 & 1.61 & 938 \\
\hline L. cristatum & 226 & 205 & L. fuscovirens & 205 &
\end{tabular}

4

$5 * \mathrm{p}<0.05, * * \mathrm{p}<0.01$

6 


\section{Figure 1}

Examples of lichens collected in this study

(A) Lichina pygmaea (B) Lichina confinis (C) Xanthoria aureola (Brittany) (D) Lathagrium auriforme (E) L. confinis sample cluster (F) X. aureola sample cluster. Photos by Delphine Parrot.
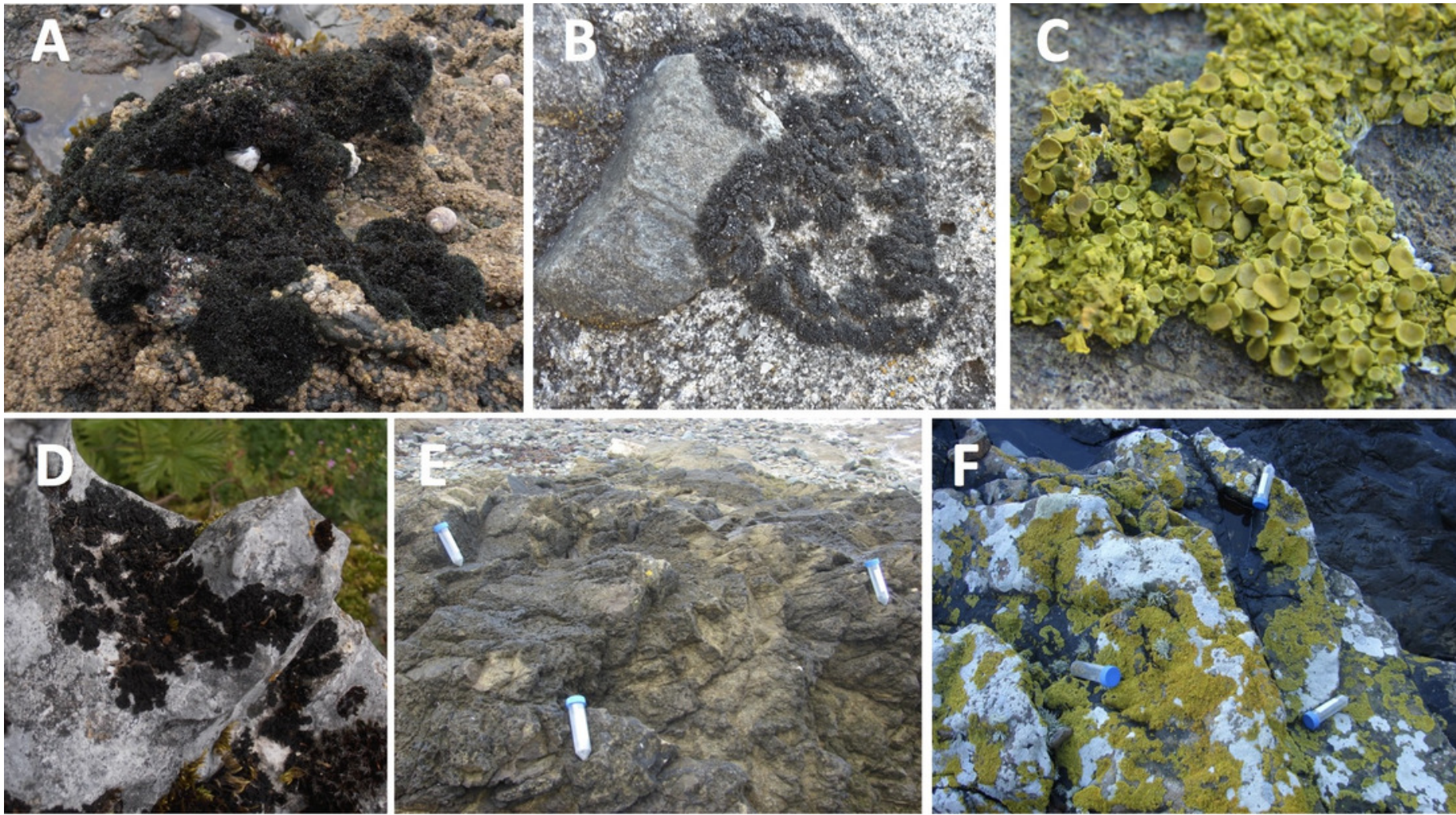
Figure 2

Alpha diversity of bacterial communities associated with marine, maritime and inland terrestrial lichens, and in seawater.

The richness and diversity metrics for the lichen species or seawater bacterial communities are displayed by position on the littoral zone for the marine and maritime lichens and the inland lichens from Austria are plotted as the Terrestrial category.

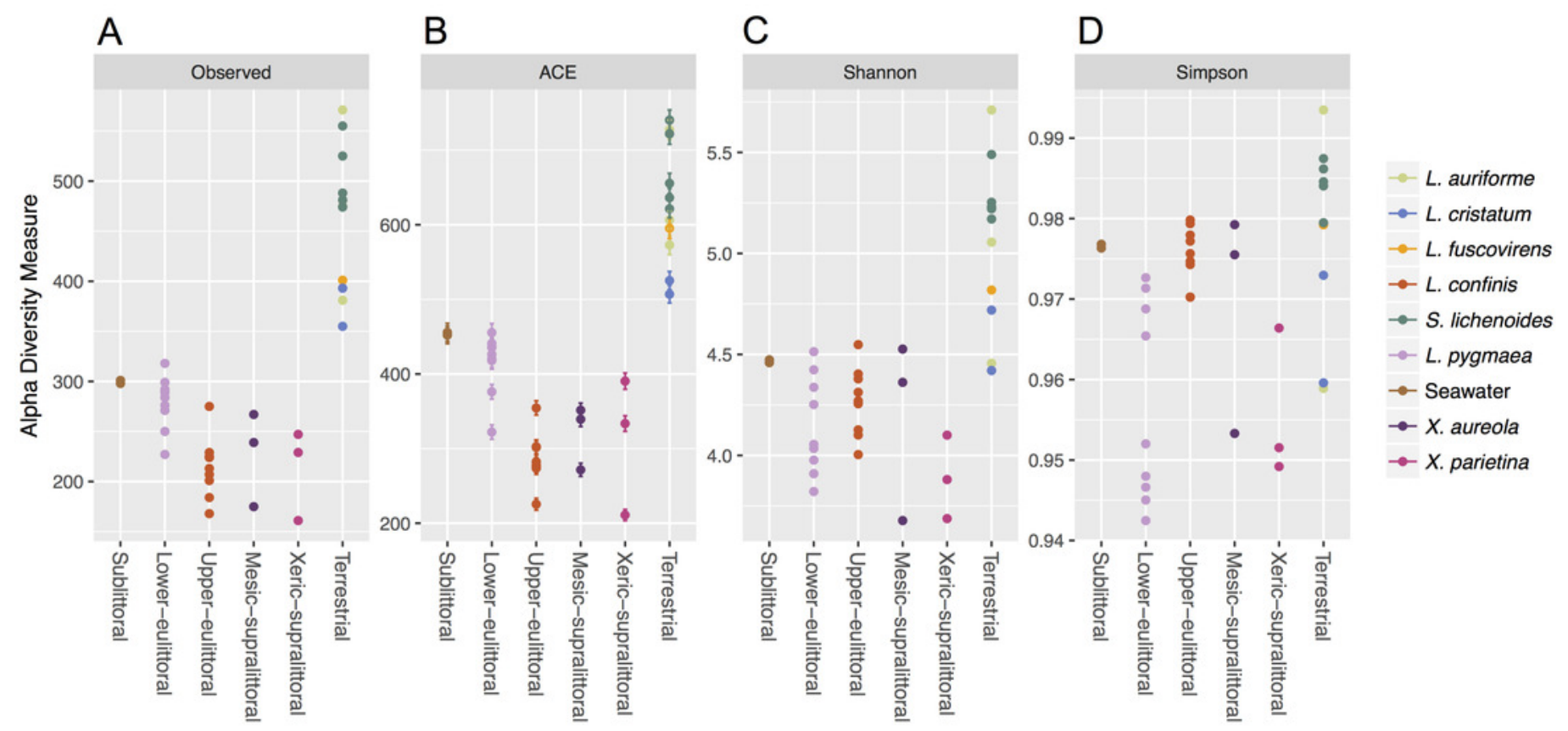


Figure 3 (on next page)

Phylogenetic diversity of the bacteria associated with different lichen species or in seawater.

The relative abundances of the major bacterial phyla and Proteobacteria classes associated with lichens or in seawater are expressed as percentages of the total sequences. Phyla that accounted for less than $2 \%$ of the total sequences were grouped together as "Other". 
PeerJ Manuscript to be reviewed

\section{Relative abundance \%}

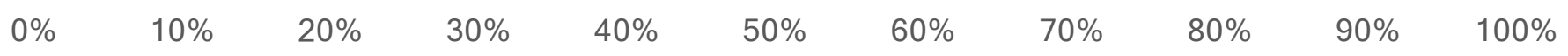

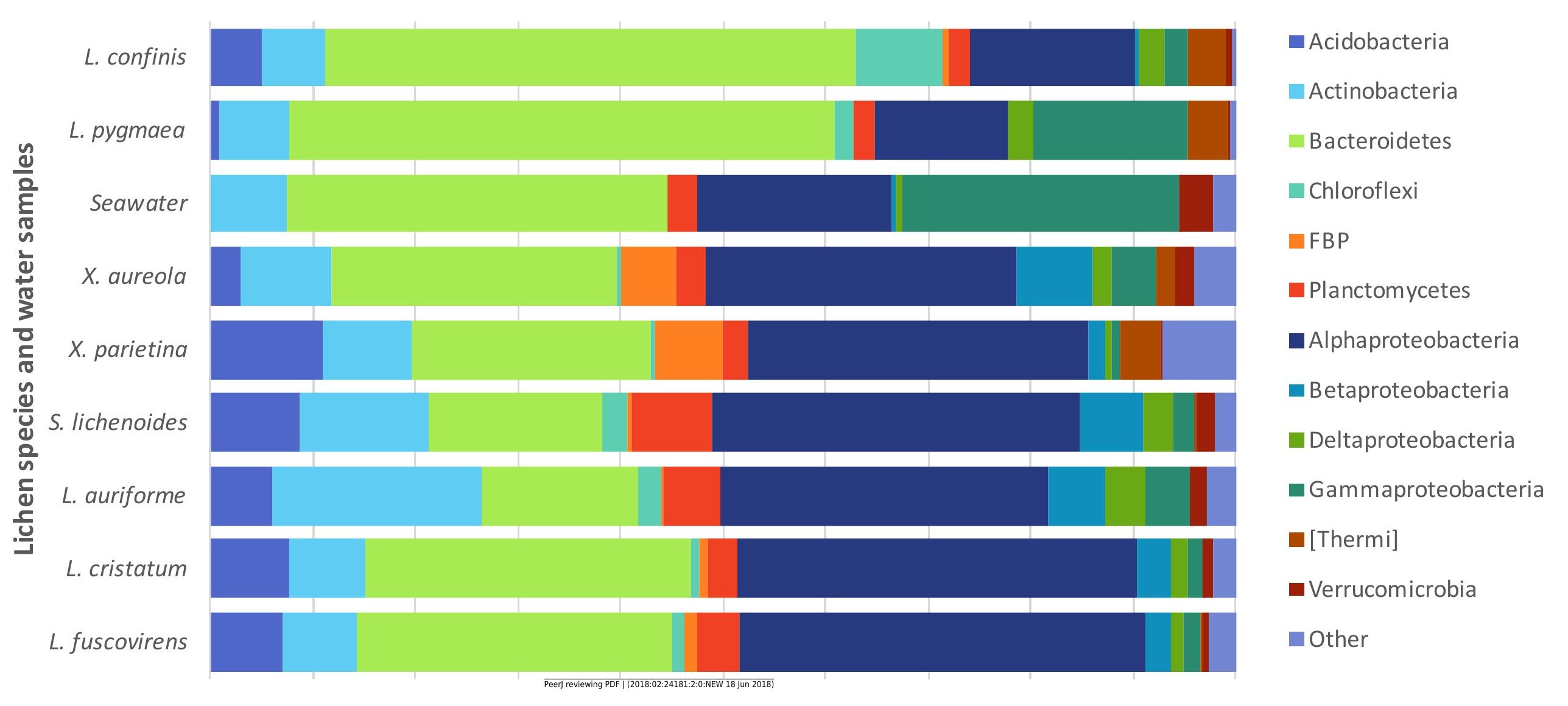




\section{Figure 4}

Beta diversity of bacterial communities associated with the lichens or seawater assessed by Bray Curtis dissimilarity and average linkage clustering.

(A) Beta diversity of bacterial communities associated with the lichens or seawater assessed by Bray Curtis dissimilarity and average linkage clustering (B) Heatmap showing the relative abundance of the 30 most abundant OTUs among either the marine or the maritime-inland terrestrial lichens. The mean sequence abundance was calculated for each lichen sample cluster or the seawater samples. Lf, L. fuscovirens; Lcr, L. cristatum; La, L. auriforme; SI, S. lichenoides; Xp, X. parietina; Xa, X. aureola; SW, seawater; LC, L. confinis; Lp, L. pygmaea. 
A

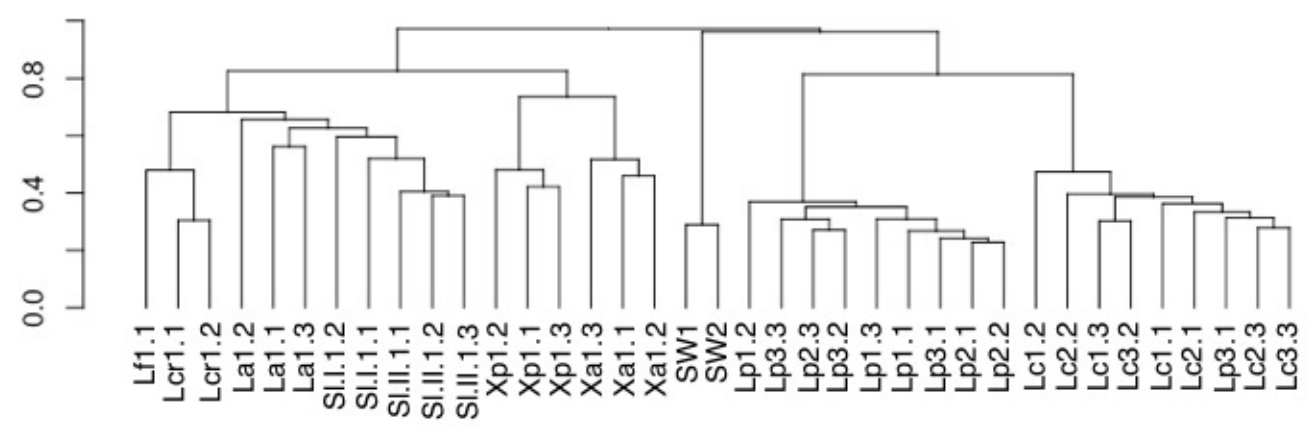

B
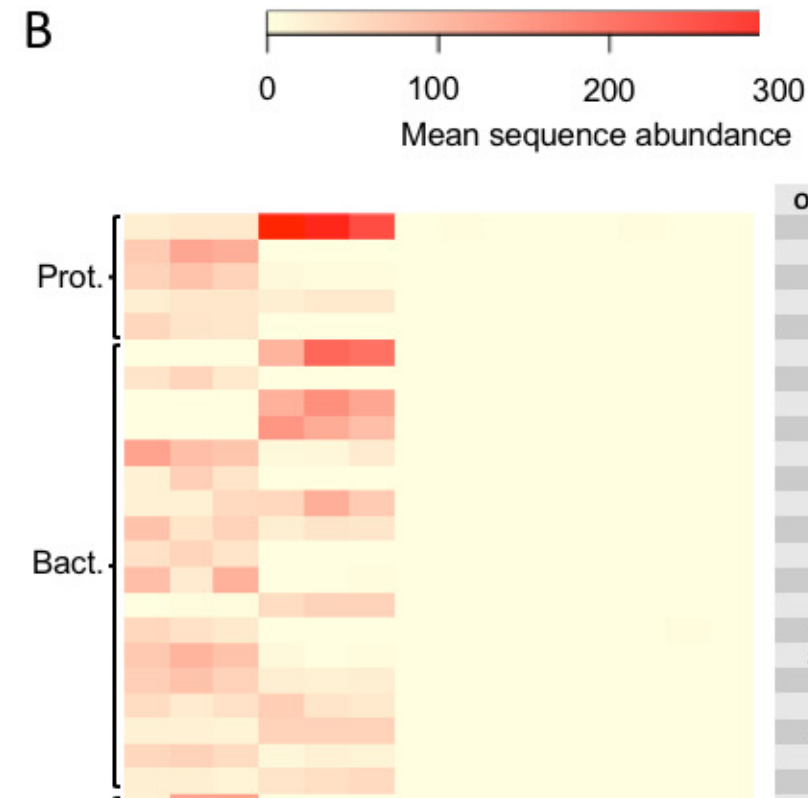

$\begin{aligned} \text { OTU } & \text { Class } \\ 15 & \text { Gammaproteobacteria } \\ 19 & \text { Alphaproteobacteria } \\ 21 & \text { Alphaproteobacteria } \\ 60 & \text { Alphaproteobacteria } \\ 94 & \text { Alphaproteobacteria } \\ 5 & \text { Flavobacteriia } \\ 40 & \text { Flavobacteriia }\end{aligned}$

Order Family Genus

Chloro.

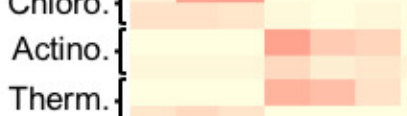

7 [Saprospirae]

6 [Saprospirae]

24 [Saprospirae]

17 Cytophagia

10 Cytophagia

75 Cytophagia

26 Cytophagia

20 Cytophagia

186 Cytophagia

250 [Rhodothermi]

50 [Rhodothermi]

25 [Rhodothermi]

147 [Rhodothermi]

79 [Rhodothermi

42 [Rhodothermi]

12 Chloroflexi

46 Anaerolineae

18 Nitriliruptoria

104 Acidimicrobiia

9 Deinococci

76 Deinococci

47 [Chloracidobacteria]

37 Alphaproteobacteria

59 Alphaproteobacteria

51 Alphaproteobacteria

16 Alphaproteobacteria

34 Alphaproteobacteria

137 Alphaproteobacteria

468 Alphaproteobacteria

54 Alphaproteobacteria

165 Alphaproteobacteria

44 Alphaproteobacteria

66 Alphaproteobacteria

95 Alphaproteobacteria

182 Alphaproteobacteria

187 Betaproteobacteria

$\begin{aligned} 100 & \text { Betaproteobacteria } \\ 31 & \text { [Chloracidobacteria] }\end{aligned}$

63 Actinobacteria

122 Actinobacteria

138 Actinobacteria

22 Cytophagia

112 Cytophagia

174 Cytophagia

23 Cytophagia

29 Cytophagia

235 [Saprospirae]

39 [Saprospirae]

77 [Saprospirae]

Rhodobacterales Rhodobacteraceae

Sphingomonadales Erythrobacteraceae

Rhodobacterales Rhodobacteraceae

Sphingomonadales Erythrobacteraceae

Flavobacteriales Flavobacteriaceae

Flavobacteriales Flavobacteriaceae

[Saprospirales] Saprospiraceae Lewinella

[Saprospirales] Saprospiraceae Lewinella

[Saprospirales] Saprospiraceae Lewinella

[Saprospirales] Saprospiraceae Lewinella

Cytophagales Flammeovirgaceae Tunicatimonas

Cytophagales Flammeovirgaceae Tunicatimonas

Cytophagales Flammeovirgaceae Tunicatimonas

Cytophagales Flammeovirgaceae

Cytophagales Flammeovirgaceae

Cytophagales Cytophagaceae Persicitalea

[Rhodothermales] Rhodothermaceae Rubricoccus

[Rhodothermales] Rhodothermaceae Rubricoccus

[Rhodothermales] Rhodothermaceae Rubricoccus

$\begin{array}{lll}\text { [Rhodothermales] } & \text { Rhodothermaceae } & \text { Rubricoccus } \\ \text { [Rhodothermales] } & \text { Rhodothermaceae } & \text { Rubricoccus }\end{array}$

[Rhodothermales] Rhodothermaceae Rubricoccus

[Rhodothermales] Rhodothermaceae Rubricoccus

[Roseiflexales]

Caldilineales Caldilineaceae

Euzebyales Euzebyaceae Euzebya

Acidimicrobiales C111

Deinococcales Trueperaceae

Deinococcales Trueperaceae

RB41 Ellin6075

Sphingomonadales Sphingomonadaceae Sphingomonas

Sphingomonadales

Sphingomonadales

Rhodospirillales

Acetobacteraceae

Acetobacteraceae

Rhodospirillales

Rhizobiales

Rhizobiales

Rhizobiales Beijerinckiaceae

Rhizobiales Myphomicrobiacea

Rhodobacteraceae

Caulobacterales

Burkholderiales

Burkholderiales

RB41

Caulobacteraceae

Comamonadaceae

Comamonadaceae

Ellin6075

Actinomycetales Micromonosporacea

Actinomycetales

Pseudonc

Cytophagales

Cytophagales

Pseudonocardiacea

Cytophagales Cytophagaceae

Cytophagales

Cytophagaceae

Cytophagaceae

Cytophagales

Cytophagaceae

[Saprospirales] Chitinophagaceae

[Saprospirales] Chitinophagaceae

Chitinophagaceae

FBP

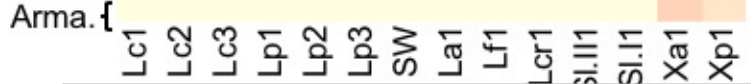

28 [Fimbriimonadia] [Fimbrimonadales] [Fimbriimonadaceae] Fimbriimonas 
Figure $\mathbf{5}$ (on next page)

Comparison of relative abundance of core or specific OTUs present in L. confinis and $L$. pygmaea.

Comparison of relative abundance of core OTUs present in (A) all replicates of both $L$. confinis and L. pygmaea or (B) the core OTUs specific for either species grouped the family level. When family level assignment was not available, the next higher taxonomic level assigned was used. (C) Venn diagram showing the number of core OTUs shared or specific to L. confinis and L. pygmaea. 
ReerJ

Core OTUs at family level for the Lichina genus

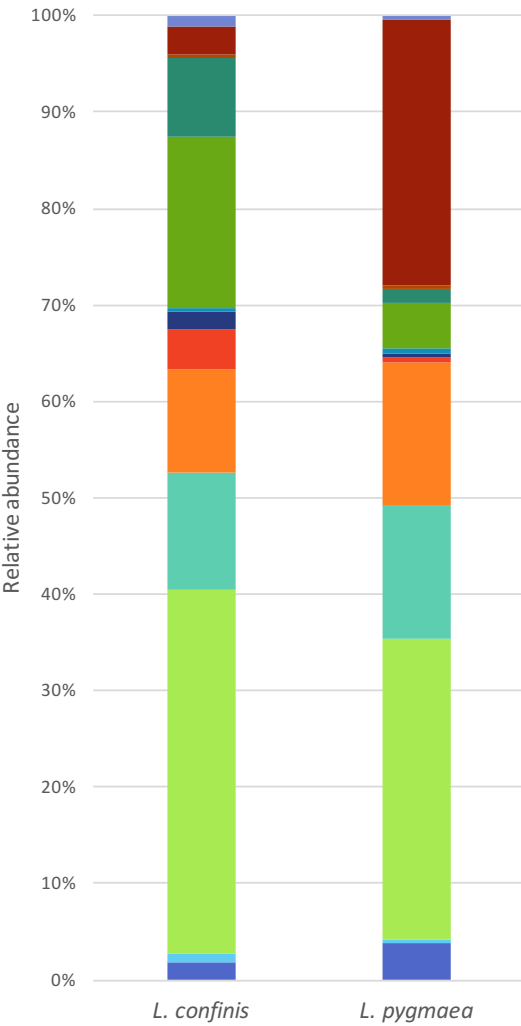

Lichen species
I f_Trueperaceae

- c_Gammaproteobacteria

- o_Myxococcales

- f_Erythrobacteraceae

- f_Rhodobacteraceae

- f__Pirellulaceae

- f_Phycisphaeraceae

- $f$ _Caldilineaceae

I__Flammeovirgaceae

- f__Saprospiraceae

II $f$ Rhodothermaceae

I._Intrasporangiaceae

a_C111

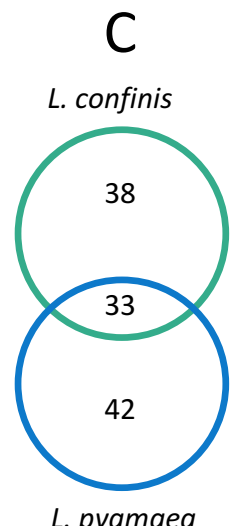

L. pygmaea

\section{B Manuscript to be reviewed}

Core OTUs at family level specific for L. confinis or L. pygmaea

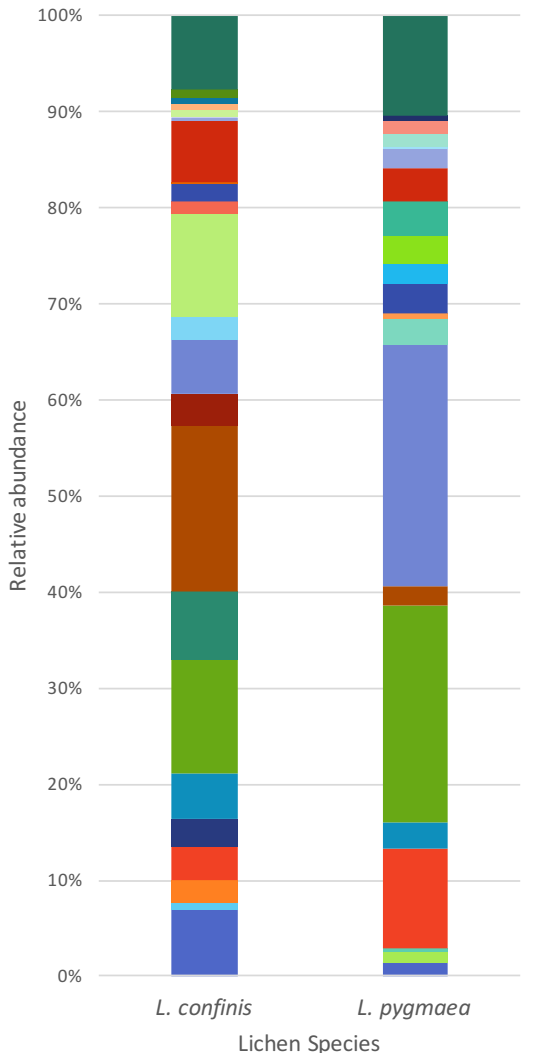

- f__Trueperaceae

- $\mathrm{f}$ [Chthoniobacteraceae]

no_Spirobacillales

- f_OM27

a Haliangiaceae

c_Deltaproteobacteria

c c Gammaproteobacteria

f__Comamonadaceae

o_Sphingomonadales

If Sphingomonadaceae

- f_Erythrobacteraceae

- $f$ Acetobacteraceae

q__Rhodobacteraceae

f__Hyphomonadaceae

no Rhizobiales

- o_Rhodospirillales

a_FBP

If_Phycisphaeraceae

a_Caldilineaceae

o_[Roseiflexales]

f_A4b

a flavobacteriaceae

- f_Cryomorphaceae

- f__Flammeovirgaceae

af_Cytophagaceae

a__Saprospiraceae

af_Rhodothermaceae

- f_Rubrobacteraceae

af_Euzebyaceae

- f_Kineosporiaceae

a_JdFBGBact

a_Intrasporangiaceae

o_Actinomycetales

-f_Ellin6075 


\section{Figure 6 (on next page)}

OTUs with significantly different relative abundances in L.confinis and L. pygmaea.

OTUs with significantly different relative abundances in L.confinis and L. pygmaea were assessed by the DESeq2 package using an adjusted $p$ value $<0.001$ and a base mean threshold $>20$. NA : OTUs not assignable at the particular taxonomic level (order or family). 


\section{Manuscript to be reviewed}

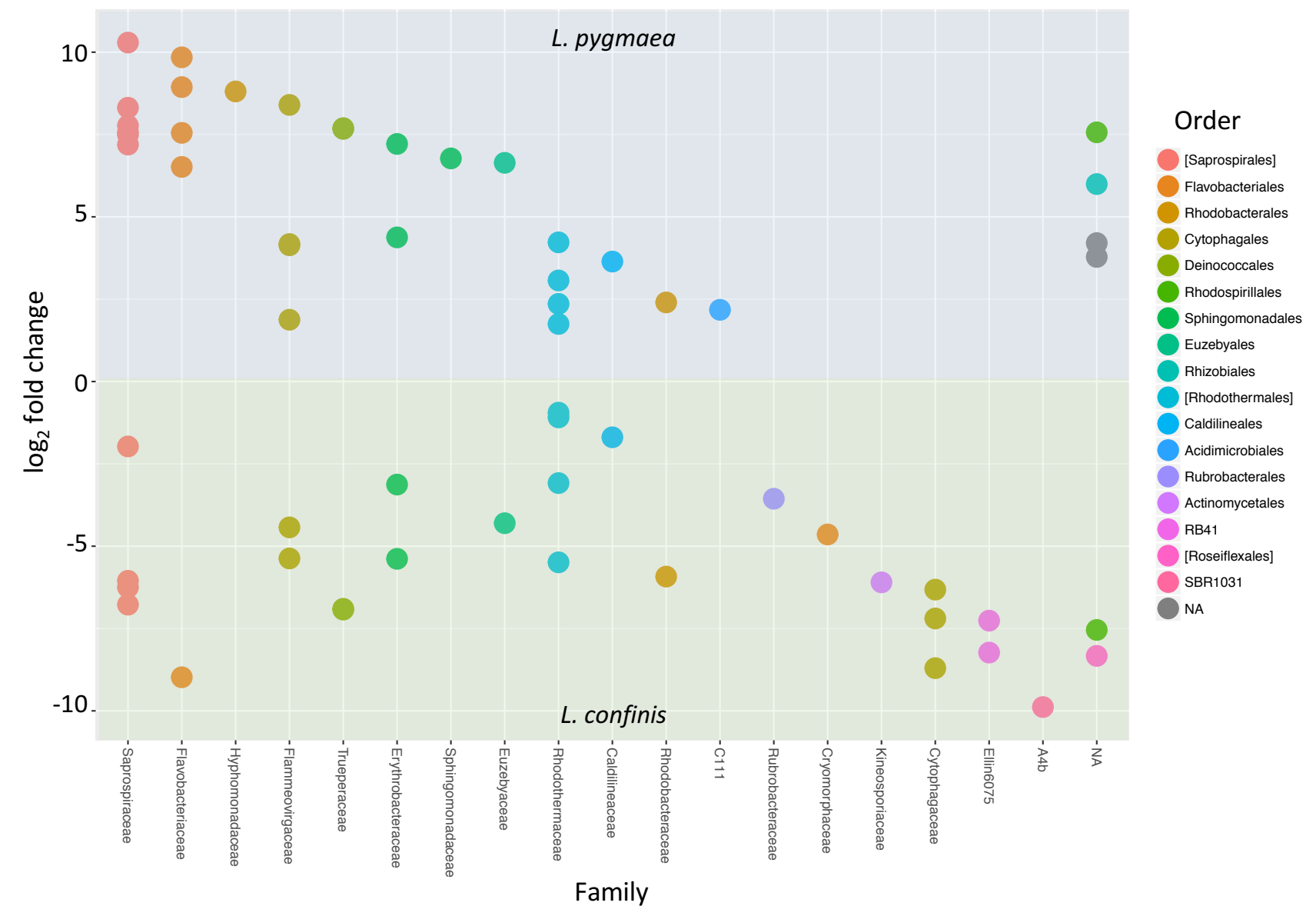

